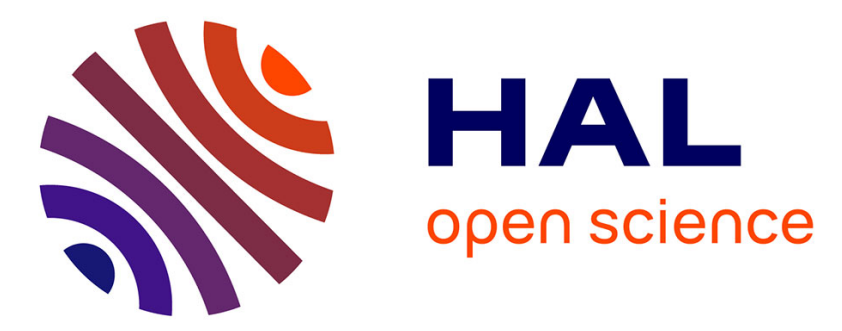

\title{
Whole layer convection in a heterogeneous planetary mantle
}

\author{
Michael Le Bars, Anne Davaille
}

\section{To cite this version:}

Michael Le Bars, Anne Davaille. Whole layer convection in a heterogeneous planetary mantle. Journal of Geophysical Research, 2004, 109 (B03), 10.1029/2003JB002617 . hal-00084090

\section{HAL Id: hal-00084090 https://hal.science/hal-00084090}

Submitted on $30 \mathrm{Jul} 2020$

HAL is a multi-disciplinary open access archive for the deposit and dissemination of scientific research documents, whether they are published or not. The documents may come from teaching and research institutions in France or abroad, or from public or private research centers.
L'archive ouverte pluridisciplinaire HAL, est destinée au dépôt et à la diffusion de documents scientifiques de niveau recherche, publiés ou non, émanant des établissements d'enseignement et de recherche français ou étrangers, des laboratoires publics ou privés. 


\title{
Whole layer convection in a heterogeneous planetary mantle
}

\author{
M. Le Bars and A. Davaille \\ Laboratoire de Dynamique des Systèmes Géologiques, Institut de Physique du Globe de Paris, France
}

Received 10 June 2003; revised 17 November 2003; accepted 1 December 2003; published 6 March 2004.

[1] Geochemical observations demonstrate that Earth's mantle is heterogeneous, but the sizes, forms, and characteristics of its reservoirs are not constrained. Using laboratory experiments, we have systematically studied a simple nonhomogeneous system, where two layers of miscible fluids with different densities, depths, and viscosities are subjected to a destabilizing temperature contrast. When the buoyancy number $B$ (i.e., the ratio of the stabilizing chemical density anomaly to the destabilizing thermal density anomaly) is lower than $0.3-0.5$, the whole layer regime develops, with a deformed interface and convective patterns over the whole tank depth. The system systematically evolves toward one-fluid Rayleigh-Bénard convection because of stirring. However, the two isolated fluids can persist for very long time compared to the characteristic timescale of thermal convection and give rise to numerous transient behaviors. Of particular interest for planetary mantles are the pulsatory dynamics, where the interface between the two layers deforms in large domes moving up and down quasiperiodically: According to the scaling laws derived from the experiments, such a mechanism could indeed provide a simple and single physical explanation for the superswells observed at present on Earth and more generally for the long-term episodicity in planetary interiors observed in geological records. INDEX TERMS: 1213 Geodesy and Gravity: Earth's interior-dynamics (8115, 8120); 8121 Tectonophysics: Dynamics, convection currents and mantle plumes; 8147 Tectonophysics: Planetary interiors (5430, 5724); KEYWORDS: thermochemical convection, planetary mantle, whole layer regime

Citation: Le Bars, M., and A. Davaille (2004), Whole layer convection in a heterogeneous planetary mantle, J. Geophys. Res., 109, B03403, doi:10.1029/2003JB002617.

\section{Introduction}

[2] The pattern of convection in Earth's mantle is today still controversial because of conflicting evidence from geophysics and geochemistry. The systematic differences in incompatible element and isotopic compositions of magma erupted at mid-ocean ridges (mid-ocean ridge basalt $(\mathrm{MORB}))$ and intraplate volcanoes (oceanic island basalt (OIB)) require the existence of heterogeneities for billions of years [Hofmann, 1997], occupying between 10\% and $75 \%$ of the mantle [Kellogg et al., 1999]. Mass balance calculations based on a bulk silicate Earth composition [Allègre, 1987] as well as heat budgets [McKenzie and Richter, 1981; Kellogg et al., 1999] also suggest the presence of at least one hidden enriched reservoir. However, the origin of these heterogeneities, as well as their precise size, shape, location, and physical characteristics, is not constrained. It was first thought that the mantle is divided in two layers at the 660-km depth seismic discontinuity, which is now known to correspond to a phase transition [Ito and Takahashi, 1989]. In this "660-layered" model [DePaolo and Wasserburg, 1976; Allègre et al., 1979; O'Nions et al., 1979] (Figure 1a), the depleted upper mantle is the source of MORB and convects separately from the lower primitive mantle producing OIB. The absence of important mass

Copyright 2004 by the American Geophysical Union. 0148-0227/04/2003JB002617\$09.00 transfer between the two layers is, however, contradicted by recent tomographic models that exhibit subducting plates in the lower mantle [e.g., Grand et al., 1997; Fukao et al., 2001]. Such motions over the whole mantle depth are expected to mix large-scale passive heterogeneities well within the lifetime of the Earth, even in the presence of viscosity increase with depth [e.g., Van Keken et al., 2002], and thus imply a "one-layer" model (i.e., convection in a fully mixed mantle, Figure 1e).

[3] Neither of these end-members models is capable of taking into account all observations, but both capture fundamental aspects of the problem. They have thus provided a reference frame for various "intermediate" proposals. Some studies have focused on the effects of the $660-\mathrm{km}$ phase transition, proposing a recent change in the style of convection [Christensen, 1995; Allègre, 1997] or an intermittent one-layer/660-layered model, where catastrophic flushing events periodically take place through the $660-\mathrm{km}$ interface [Machetel and Weber, 1991]. However, recent numerical calculations at Earth-like convective vigor demonstrate that the phase transition alone is inadequate to maintain part of the mantle unmixed [Van Keken et al., 2002]. Other studies have emphasized the importance of subduction, which continuously reintroduces heterogeneities that might sink at the bottom of the mantle, generating density and viscosity gradients, possibly even a new layer [Davies, 1984; Gurnis, 1986; Christensen and Hofmann, 1994; Albarède, 1998; Coltice and Ricard, 1999; Albarède and 
a)

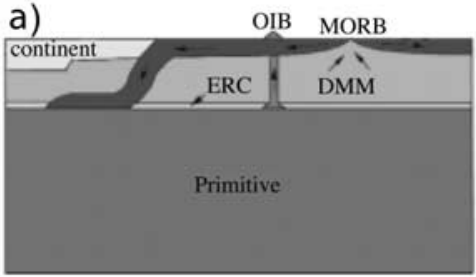

b)

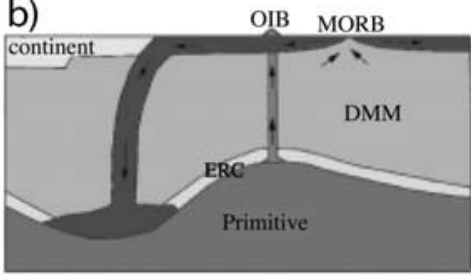

C)

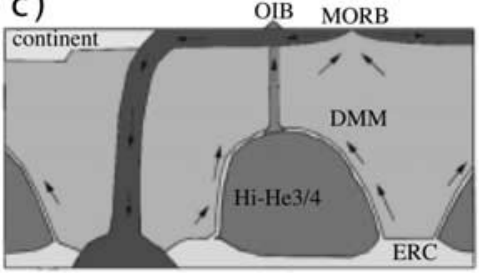

d)

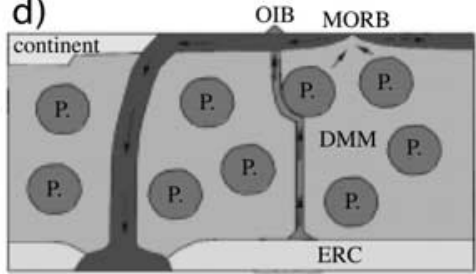

e)

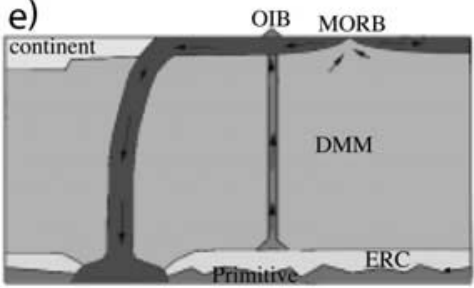

f) $\digamma^{\text {cooled copper plate }} \mathrm{T}_{2}$

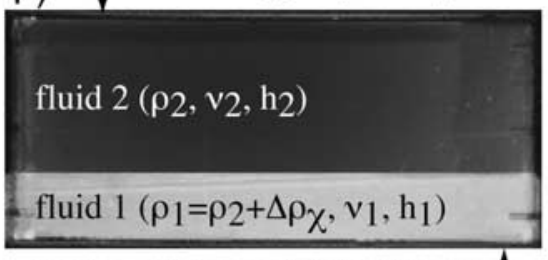

heated copper plate $\mathrm{T}_{1}=\mathrm{T}_{2}+\Delta \mathrm{T} \stackrel{A}{A}$

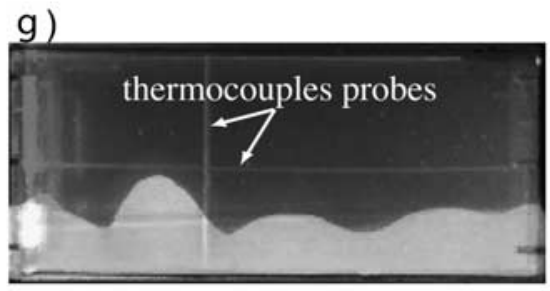

h)

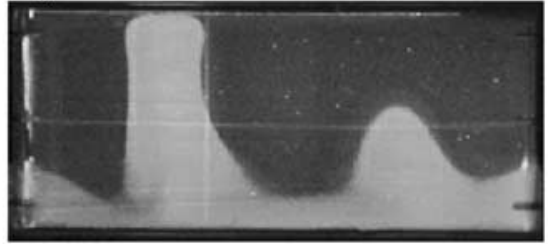

i)

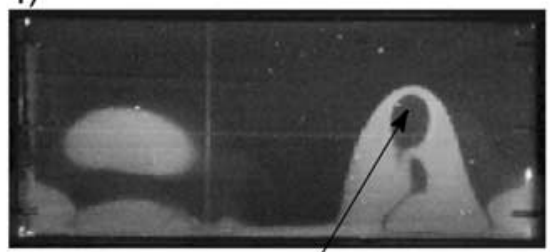

j) encapsulated blob

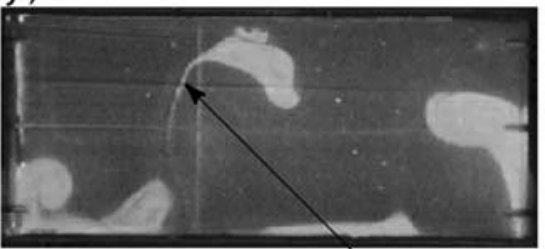

k)

filament

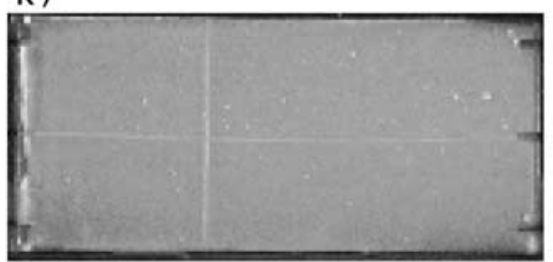

Figure 1. Proposed models of mantle convection (sketches from Tackley [2000], DMM, depleted MORB mantle; ERC, enriched recycled crust) and comparison with the time evolution of experiment $52(\gamma=140$, $a=0.30, R a=2.4 \times 10^{7}, B=0.30$ ): (a) 660-layered mantle; (b) undulating deep layer [Kellogg et al., 1999; Samuel and Farnetani, 2003]; (c) primitive piles [Tackley, 1998; Hansen and Yuen, 2000] and oscillating doming [Davaille, 1999b]; (d) primitive blobs [Davies, 1984; Manga, 1996; Becker et al., 1999; Merveilleux du Vignaux and Fleitout, 2001]; (e) one-layer model; (f) $t=0 \mathrm{~min}$; (g) $t=23 \mathrm{~min}$; (h) $t=28 \mathrm{~min}$; (i) $t=40 \mathrm{~min}$; (j) $t=125 \mathrm{~min}$; (k) $t=350 \mathrm{~min}$. See color version of this figure in the HTML.

Van der Hilst, 2002]. The recycling of oceanic crust definitely plays an important role in the global geochemical budget [Hofmann, 1997], but its ability to explain the whole range of evidence remains to be demonstrated.
Numerous works have also proposed the existence of a second reservoir with various geometries, independently of the $660-\mathrm{km}$ limit: it could take the form of an undulating deep layer [Kellogg et al., 1999; Samuel and Farnetani, 
2003] (Figure 1b), of two giant piles under Africa and French Polynesia, respectively [Tackley, 1998; Hansen and Yuen, 2000] (Figure 1c), of pulsating domes moving up and down quasiperiodically [Davaille, 1999b] (Figure 1c), or of viscous blobs encapsulated in the whole convecting mantle [Davies, 1984; Manga, 1996; Becker et al., 1999; Merveilleux du Vignaux and Fleitout, 2001] (Figure 1d). All these models are conceptually attractive and each gives a plausible explanation for selected observations. However, several questions remain unanswered regarding the origin and duration of these complex geometries.

[4] In our study, we have addressed the problem of mantle convection from a "fluid dynamics" point of view through laboratory experiments [Davaille, 1999a; Le Bars and Davaille, 2002, 2004]. Since we know that Earth's mantle is heterogeneous in composition [e.g., Kellogg et al., 1999] and viscosity [Davies, 1984; Manga, 1996; Becker et al., 1999; Merveilleux du Vignaux and Fleitout, 2001], we have focused on the simplest case of nonhomogeneous thermal convection, i.e., a two-layer system. We do not want to debate about the origin of the second reservoir, which could for instance be created by slabs remnant [e.g., Christensen and Hofmann, 1994], delaminated continental material, relics of a primitive mantle [e.g., Tackley, 1998; Kellogg et al., 1999], chemical infiltration from the core [e.g., Hansen and Yuen, 1988]. Our purpose is to provide a systematic theoretical and experimental description of the interaction of thermal convection with stratification in viscosity and density that could be applied to any given reservoir in the mantle.

[5] The setup of our experiments is shown in Figure 1f: two miscible fluids with different kinematic viscosities $\left(\nu_{1}\right.$ and $\left.\nu_{2}\right)$, densities $\left(\rho_{10}\right.$ and $\rho_{20}$ at temperature $\left.T_{0}\right)$ and depths $\left(h_{1}\right.$ and $\left.h_{2}\right)$, initially at ambient temperature, are superimposed in a tank. Viscosities are composition- and/or temperature-dependent. Initially, the density distribution is stable, and the interface is flat. At time $t=0$, the lower (upper) copper plate is continuously heated (cooled) until the bath has reached its assigned temperature $T_{1}\left(T_{2}\right)$, and thermal effects can possibly reversed the chemical stratification. Four dimensionless numbers are necessary to fully describe the two-layer system, in addition to the Prandtl number taken as infinite (as in Earth's mantle):

1. The viscosity ratio is

$$
\gamma=\frac{\nu_{1}}{\nu_{2}}
$$

2. The layer depth ratio is

$$
a=\frac{h_{1}}{H},
$$

where $H=h_{1}+h_{2}$.

3. The buoyancy number, ratio of stabilizing chemical density anomaly to destabilizing thermal density anomaly, is

$$
B=\frac{\Delta \rho_{\chi}}{\alpha \rho_{0} \Delta T},
$$

where $\Delta \rho_{\chi}=\rho_{10}-\rho_{20}$ is the chemical stratification, $\alpha$ is the thermal expansion coefficient, $\rho_{0}=\rho_{10}+\rho_{20} / 2$ and $\Delta T=T_{1}-T_{2}$.

\section{The Rayleigh number is}

$$
R a=\frac{\alpha g \Delta T H^{3}}{\kappa \nu_{2}}
$$

where $\kappa$ is the thermal diffusivity coefficient. It is sometimes more convenient to use the Rayleigh number of each layer taken separately

$$
R a_{i}=\frac{\alpha g \Delta T_{i} h_{i}^{3}}{\kappa \nu_{i}}
$$

where $\Delta T_{i}$ is the temperature contrast through layer $i$. As a first-order approximation, one can take [Le Bars and Davaille, 2004]

$$
R a_{1}=R a \times \frac{a^{3}}{2 \gamma} \text { and } R a_{2}=R a \times \frac{(1-a)^{3}}{2} .
$$

[6] Depending on the buoyancy ratio $B$, three regimes were found as shown in Figure 2: (1) at $B>1$, convection develops above and/or below the flat interface [Richter and Johnson, 1974; Olson, 1984], where fixed, long-lived thermochemical plumes are generated (i.e., "stratified regime"); (2) at $B<0.3-0.5$, the interface is destabilized [Olson and Kincaid, 1991] and motions develop over the whole tank (i.e., "whole layer regime"); and (3) at intermediate values $(0.3-0.5<B<1)$, the interface remains stable, but is largely deformed by thermal features coming from the outer boundaries (i.e., "dynamic topography"). Applied to the Earth [Davaille et al., 2003], strongly stratified convection with a nearly flat interface in the midmantle would require a chemical density contrast typically greater than $5 \%$ (i.e., $B>1$ ). This seems mostly precluded in the mantle today, since both seismic models [Dziewonski and Anderson, 1981] and mineral physics studies ([Jackson, 1998]) indicate that present-day planetwide density stratification of chemical origin cannot exceed a few percent [Bina, 1998]; one must, however, notice that strong stratification may be present locally, as for instance in $\mathrm{D}^{\prime \prime}$ [Tackley, 1998; Davaille, 1999b], where thermochemical plumes could develop out of a stratified thermal boundary layer (Figure 2b). For planet-wide density stratification between 2 and $5 \%$ with an interface in the midmantle, our study shows that stratified convection would occur but with a highly distorted interface. In a careful study of the seismic signatures produced by thermochemical features, Tackley [2002] showed that present-day observations could be consistent with the presence of piles of denser material at the bottom of the mantle, located under lower mantle uprisings. From a fluid dynamics point of view, those piles would be explained by dynamic topography of a initially slightly stratified layer, which would remain quite stable for a long time. The whole layer regime would take place in the Earth for density anomalies typically smaller than $2 \%$. As shown in our laboratory experiments, the whole layer regime can not be assimilated to the one-layer regime: even very small density contrasts can perturb convection for a very long time and give rise to numerous transient behaviors with two distinct fluids before homog- 
(a)

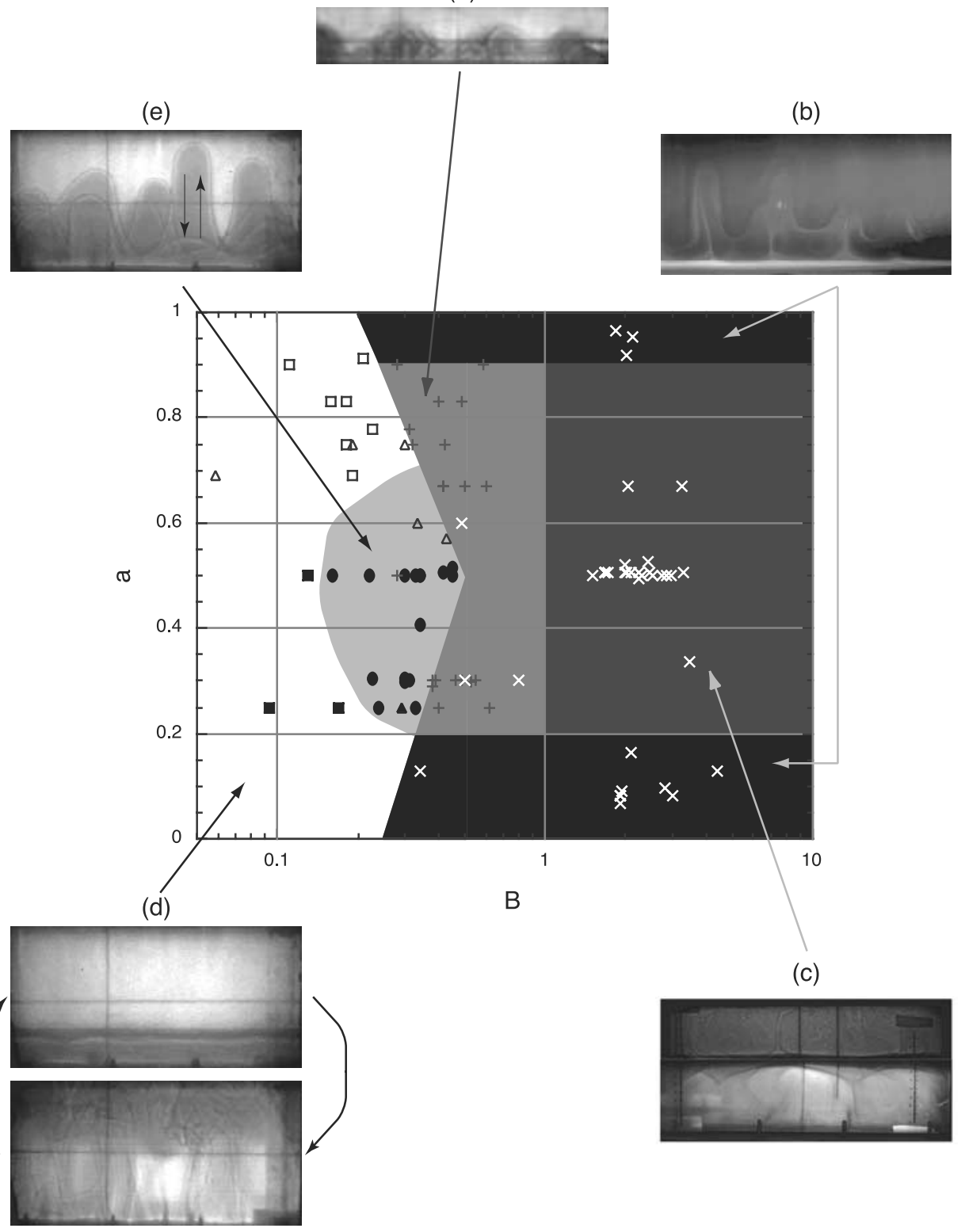

Figure 2. Regimes diagram as a function of the buoyancy number $B$ and the layer depth ratio $a$. Pluses represent stratified experiments with interface deformations as in Figure 2a (i.e., "dynamic topography"). Crosses stand for stratified regime with a flat interface: thermochemical plumes shown in Figure $2 \mathrm{~b}$ take place when one layer is thinner than the corresponding thermal boundary layer [see Davaille et al., 2002]; when both layers are large enough, convection develops above and below the interface as in Figure 2c. The other symbols represent the various forms of whole layer regime: triangles correspond to immediate mixing, squares correspond to initial configuration reversals illustrated in Figure 2d, and circles correspond to vertical oscillations illustrated in Figure 2e; open symbols correspond to domes from the less viscous fluid under the form of cavity plumes (Figure $3 \mathrm{~b}$ ) and solid symbols correspond to domes from the most viscous fluid under the form of diapirs (Figure 3c). Experimental tanks are $30 \times 30 \mathrm{~cm}$ large, and 6,8 , or $14.8 \mathrm{~cm}$ high. See color version of this figure in the HTML.

enization (Figures 2d, 2e, 3a, 3b, and 3c), which are the focus of the present paper.

[7] Because of small-scale entrainment and large-scale stirring, the density contrast, thus the buoyancy number, progressively decreases through time [Davaille, 1999a] and all the experiments, even starting with a large stratification, systematically evolve toward the fully mixed state, as illustrated in Figures 1f $-1 \mathrm{k}$ : an initially layered system (Figure 1f) progressively gives rise to small interface undulations (Figure 1g), then to large piles (Figure 1h), then to whole tank pulsations (Figures $1 \mathrm{~h}$ and 1i). Even when the two-layer system is destroyed, chemical heterogeneities still exist inside the tank (Figure 1j), which are progressively erased by advection and ultimately chemical 
(a)

(c)

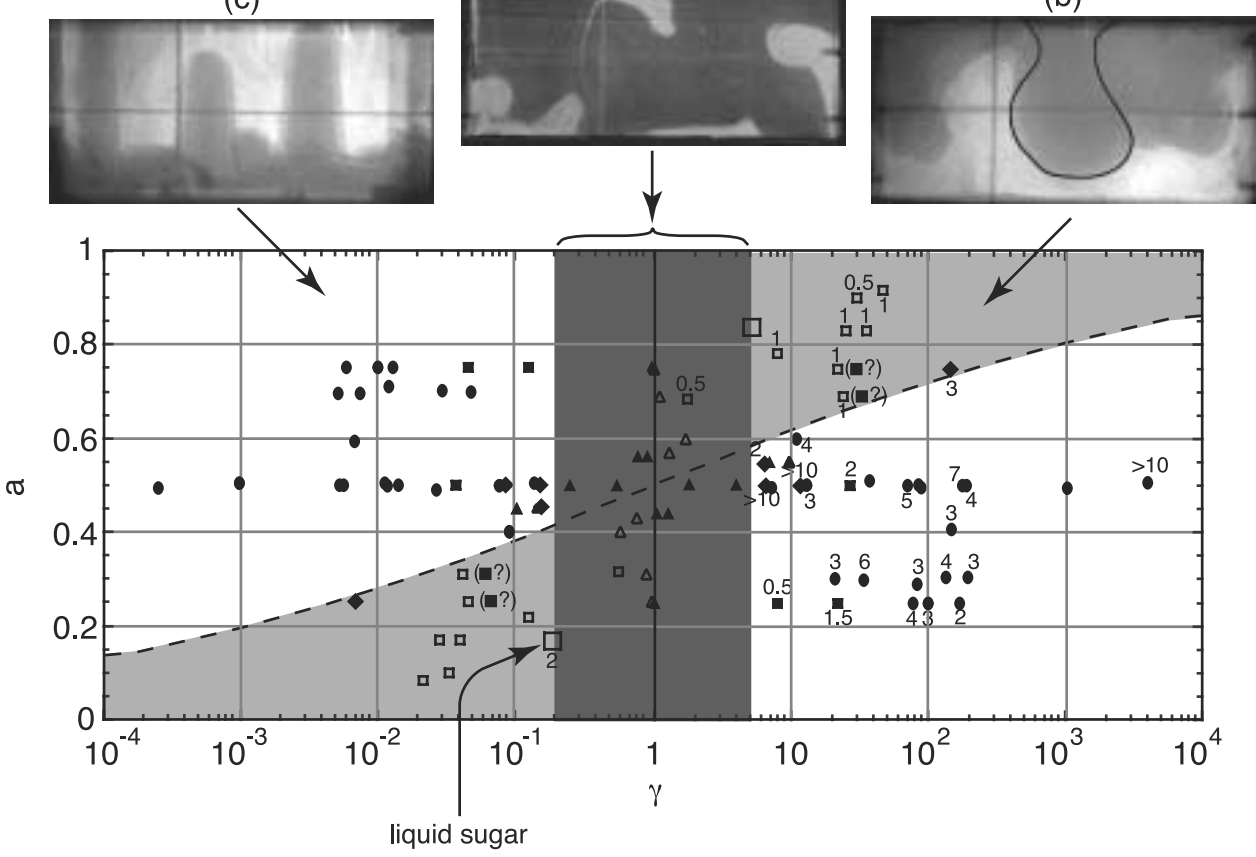

Figure 3. Behavior and spouting direction as a function of viscosity and layer depth ratios: open points correspond to cavity plumes shown in Figure $3 \mathrm{~b}$ (light shaded area), and solid points correspond to diapiric plumes shown in Figure 3c (white area). The dashed line represents the theoretical law (8). Triangles stand for overturning and immediate mixing as illustrated in Figure 3a (dark shaded area), diamonds stand for oscillations close to marginal stability [see Le Bars and Davaille, 2002], circles stand for "vertical oscillations" (Figure 1e), and squares stand for "initial configuration reversals" (Figure 1d); the numbers near the symbols indicate the number of observed pulsations, from 0 to $>10$. In our experiments, because of technical constraints, the lower layer was always the most viscous (i.e., $\gamma \geq 1$ ), except for the liquid sugar experiment (i.e., temperature-dependent viscosity). However, since the equations of motion are identical by interchanging $(\gamma, a)$ and $(1 / \gamma, 1-a)$ [Le Bars and Davaille, 2002], we expect that similar results will be observed with a less viscous lower layer, and symmetrical points are also reported here. See color version of this figure in the HTML.

diffusion. The system finally ends up in one-layer convection (Figure 1k), which is only the final state of whole layer convection. The typical duration of this evolution depends on the initial values of $B, \gamma$, and $a$ [Davaille, 1999a]. These experimental results suggest that the mantle is not in a steady state: its convective regime has evolved through Earth's history, and all patterns described in Figures 1a1e could successively have taken place through time. Such an evolution was also partly observed in numerical simulations, starting from a linear chemical profile [Hansen and Yuen, 2000]. Calculations over Earth's parameters ranges demonstrate that a typical density stratification of $2 \%$ is erased over Earth's history [Davaille et al., 2003]. This means for instance that a lower "primitive" reservoir (i.e., stratification inherited from the early differentiation of the Earth), characterized by an initial interface location at $660 \mathrm{~km}$ depth (i.e., the upper bound given by geochemical evidence [Hofmann, 1997]), an initial stratification of $3 \%$, and initial viscosities of $10^{20} \mathrm{~Pa} \mathrm{~s}$ in the upper mantle, $100 \times 10^{20} \mathrm{~Pa} \mathrm{~s}$ in the lower mantle, would partly persist up to now and would be in the whole layer regime today (e.g., Figure 4). The purpose of the present paper is to describe the physical and geophysical signatures of whole layer behaviors in a heterogeneous planetary mantle. For the sake of simplicity, our system is always initially stratified in two layers of different densities and viscosities; we then observe its destabilization and temporal evolution. In section 2 , we will describe the fluid mechanics characteristics of this regime and apply the scaling laws defined in our systematic study [Le Bars and Davaille, 2004] to the parameter range likely to be relevant to planets. We will then see to what extent this "messy" whole layer convection can explain the geological data and be related to natural observations. In section 4 , we will finally estimate how the main conclusions of our simple analogical model would change when taking into account more realistic Earth-like ingredients.

\section{Experimental Constraints on Whole Layer Convection}

[8] Through our laboratory experiments [Davaille, 1999a; Le Bars and Davaille, 2002, 2004], we have explored large ranges of buoyancy and Rayleigh numbers in order to characterize the various behaviors described in section $1\left(0.048<B<4.4\right.$ and $\left.32<R a<6.1 \times 10^{8}\right)$. In the present paper, we will focus on ranges relevant for planetary 


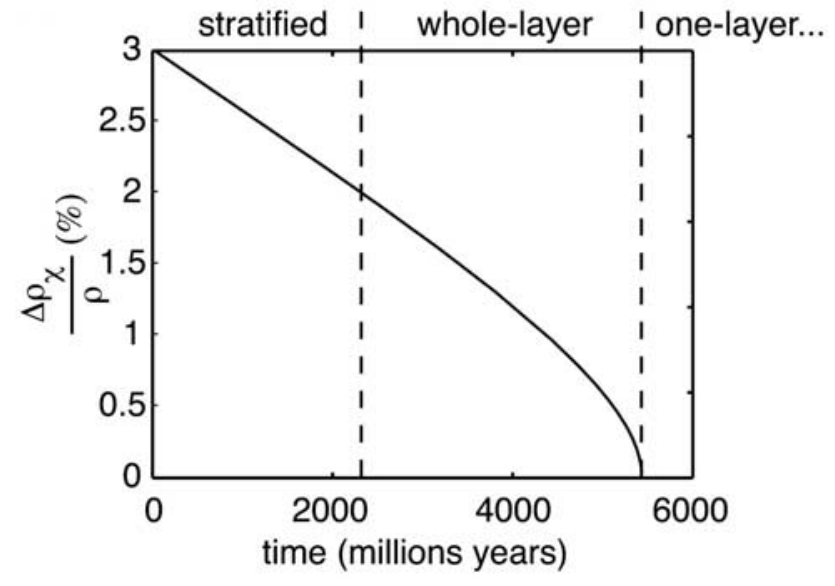

Figure 4. Typical evolution of the density contrast in a two-layer mantle, obtained with the scaling laws of Davaille [1999a]. The interface was originally located at the transition zone, the initial density contrast was $3 \%$ and the initial viscosity contrast was 100 . The whole mantle regime starts for a typical density contrast of $2 \%$ : several largescale pulsations are then expected to take place. One-layer convection (i.e., convection in a fully mixed mantle) is only reached after 5400 Myr.

mantles in the whole layer regime, as given in Table 1. For each of the following applications, one or two free parameters are systematically changed in the proposed limits, whereas the others are taken at the "fixed" reference value.

\subsection{Observed Behaviors and Patterns}

[9] In our experiments, the two fluids are initially at the same temperature $T_{0}$, then heated from below and cooled from above. Outer thermal boundary layers subsequently grow from hot and cold plates. Depending on the local Rayleigh number, they can either keep growing by conduction or destabilize under the form of small thermal plumes: these features correspond to classical Rayleigh-Bénard convection inside each layer separately, and their dynamics are fully characterized by the layer Rayleigh number $R a_{i}$ [see Le Bars and Davaille, 2004].

[10] In all cases, the lower fluid is progressively heated and becomes lighter, whereas the upper fluid is cooled and becomes heavier. Once the chemical density anomaly is cancelled by thermal effects, the interface becomes unstable. The pattern of destabilization then depends on the direction of doming, as observed in the closely related case of Rayleigh-Taylor instabilities [Whitehead and Luther, 1975]: we observe either domes developing from the most viscous fluid into the less viscous one under the form of large vertical cylinders called "diapiric plumes" separated by cusps (Figure 3c) or domes developing from the less viscous fluid into the most viscous one under the form of large blobs followed by a thinner tail, comparable to cavity plumes (Figure $3 \mathrm{~b}$ ). The direction of spouting is determined by the relative value of two parameters, characterizing the "penetrability" of each layer [Ribe, 1998]: (1) the viscosity ratio, since it is easier to penetrate a less viscous layer, and (2) the layer depth ratio, since it is easier to invade a deeper layer, where boundary conditions do not limit motions. In our experiments, deformations tend to develop through the layer were motions are easier, thus through the layer with the highest $R a_{i}$. The doming direction then changes when

$$
R a_{1}=R a_{2}
$$

which means at first order, using equation (6),

$$
a=\frac{1}{1+\gamma^{-1 / 3}},
$$

in agreement with our experiments (Figure 3).

[11] Once thermochemical domes reach the opposite boundary, they loose their thermal buoyancy and the initial chemical stratification reappears. The further evolution of the system mainly depends on the viscosity ratio.

\subsubsection{Overturning}

[12] When $1 / 5 \leq \gamma<5$ typically (Figure 3 ), the two-layer initial system is never reconstructed: domes break up into smaller-scale blobs upon overturning and immediate stirring operates; the two layers are very rapidly mixed, as described by Olson and Kincaid [1991].

\subsubsection{Pulsations}

[13] When $\gamma<1 / 5$ or $\gamma>5$ typically, the whole layer regime gives rise to large-scale oscillations: the two fluids conserve their own identity, and the initial two-layer system is periodically reconstructed. The number of observed pulsations rapidly increases with $\gamma$ (Figure 3). Two mechanisms of initial system reconstruction are possible, namely, vertical oscillations and initial configuration reversals:

[14] 1. The typical evolution of vertical oscillations is presented in Figures 5c, 5d, and 5e. In this case, domes loose their thermal buoyancy very rapidly after reaching the opposite boundary plate: they then collapse on themselves and the two-layer initial system is regenerated, ready for another cycle to begin. In going back to initial state, the invader fluid can encapsulate blobs of the other layer, and mixing slowly occurs by advection. However, as many as eight successive oscillations have been observed.

[15] 2. Initial configuration reversals are presented in Figures 5f, 5g, and 5h. They correspond to the behavior predicted by Herrick and Parmentier [1994]: the whole invading layer is progressively emptied, until the initial configuration is totally reversed, with fluid 1 lying above fluid 2 . Then, fluid 1 cools down, fluid 2 heats up, and the system finally goes back to initial state. In this case, stirring also works by advection, but several successive reversals have been observed.

[16] Vertical oscillations take place when domes cool down (respectively heat up) faster than they spread out in the vicinity of the cold plate (respectively hot plate), and rapidly collapse into initial state: it thus happens when the restoring force due to chemical stratification is predominant

Table 1. Range of Parameters Used in This Paper ${ }^{\mathrm{a}}$

\begin{tabular}{ccc}
\hline Free Parameters & Total Range & Fixed Value \\
\hline$\gamma$ & $10^{-3}-10^{3}$ & $10^{-1}$ \\
$a$ & $0-1$ & 0.3 \\
$R a$ & $10^{5}-10^{10}$ & $1.3 \times 10^{7}$ \\
$B$ & $0-0.5$ & 0.17 \\
\hline
\end{tabular}

${ }^{\mathrm{a}}$ Fixed values correspond to our preferred values determined for the present state of Earth's mantle (see section 3.1). 
a)

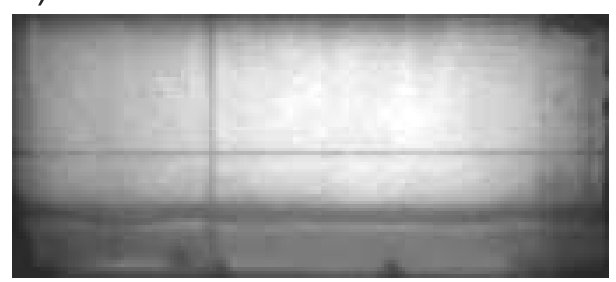

b)

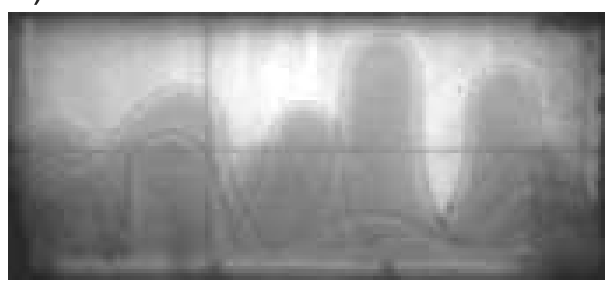

c)

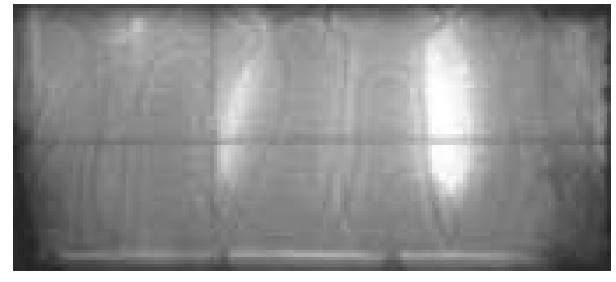

d)

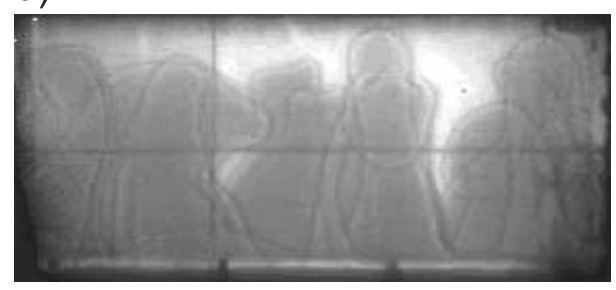

e)

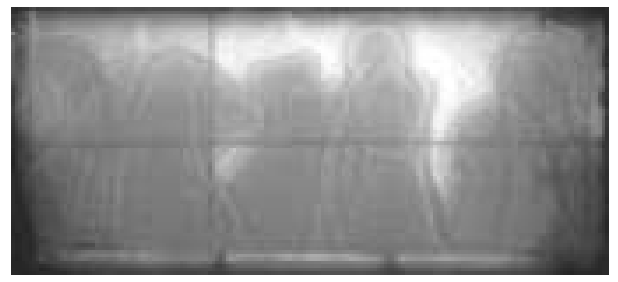

f)

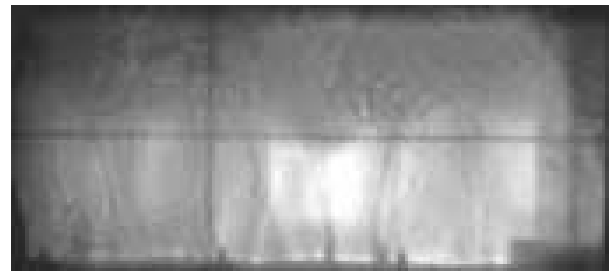

g)

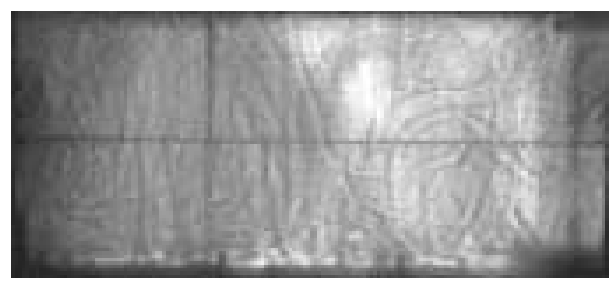

h)

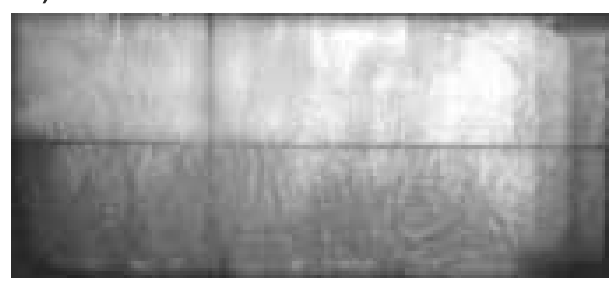

Figure 5. Pictures of whole layer regimes: $(\mathrm{a}, \mathrm{b})$ common onset; $(\mathrm{c}, \mathrm{d}, \mathrm{e})$ vertical pulsation in experiment $18\left(\gamma=21, a=0.30, R a=8.8 \times 10^{6}, B=0.31\right)$, and (f, g, h) initial configuration reversal in experiment $9\left(\gamma=22, a=0.25, R a=1.5 \times 10^{7}, B=0.17\right)$. These two mechanisms could respectively illustrate the formation of superswells in the Earth and the resurfacing of Venus (see section 3). See color version of this figure in the HTML.

compared to the thermal buoyancy, that is when the buoyancy number is relatively large $(B>0.2-0.3$ typically, see Figure 2) and/or the Rayleigh number relatively small. On the contrary, initial configuration reversals take place when the chemical stratification is low compared to the thermal buoyancy $(B<0.2$ typically and/or large $R a)$, but also when the invading layer is small and thus rapidly emptied $(a<0.3$ or $a>0.7$, see Figure 2).

\subsection{Thermal Signature of Whole Layer Convection}

[17] The whole layer regime is excited (i.e., the interface is fully destabilized) once the thermal buoyancy around the 
interface is large enough to induce motions over the whole depth of the tank in spite of thermal diffusion, viscous dragging and chemical stratification.

[18] A first-order approach consists in forgetting the real thermal and chemical variations and only considering a constant mean density in each layer with a sharp change at the interface:

$$
\overline{\rho_{i}}=\rho_{i 0}-\overline{\alpha \rho_{0}\left(T-T_{0}\right)_{i}},
$$

where $\overline{\alpha \rho_{0}\left(T-T_{0}\right)_{i}}$ is the mean value of thermal buoyancy $\alpha \rho_{0}\left(T-T_{0}\right)$ over the layer $i$. Such a system is then comparable to Rayleigh-Taylor configurations (see, for instance, Whitehead and Luther [1975]) and becomes unstable provided

$$
\overline{\rho_{1}}<\overline{\rho_{2}} \text {. }
$$

In terms of buoyancy number, equation (10) means that the effective buoyancy number based on real chemical and thermal contrasts

$$
B_{\text {eff }}(t)=\frac{\Delta \rho_{\chi}(t)}{\overline{\alpha \rho_{0}\left(T-T_{0}\right)_{1}}-\overline{\alpha \rho_{0}\left(T-T_{0}\right)_{2}}}
$$

becomes strictly lower than 1. In our experiments, we measured a mean critical value at onset

$$
B_{c}=0.98 \pm 0.12
$$

for $0.51<a<0.83,1.3<\gamma<25$, and $1.7 \times 10^{6}<R a<$ $7.5 \times 10^{7}$.

[19] This simplified model focuses on the influence of the chemical stratification on the destabilization: for the whole layer regime to be excited, thermal effects have to reverse the initial density contrast, which is indeed the predominant effect at large $R a$. It implicitly neglects thermal and viscous diffusions during motions over the whole depth of the tank, which should somewhat influence the value of $B_{c}$. However, the difficulty of measuring $B_{\text {eff }}$ experimentally does not allow us to recover any systematic dependence.

[20] Taking $\alpha$ as a constant in equation (11), the onset of whole layer regime is given by

$$
B_{\text {eff }}(t)=\frac{\Delta \rho_{\chi}(t)}{\alpha \rho_{0} \theta(t)}=B_{c}
$$

where $\theta(t)$ is the typical temperature contrast between the two reservoirs at a given time. Then at onset,

$$
\theta(t)=\frac{B}{B_{c}} \Delta T \sim(1.02 \pm 0.12) \times B \Delta T
$$

using equation (12). For the initial destabilization, the thermal contrast between the two fluids has to increase from 0 (initially isothermal fluids) to the critical value $1.02 \times$ $B \Delta T$. The total density anomaly, taking into account both thermal and chemical effects, is then given by

$$
\Delta \rho_{\mathrm{eff}}=\alpha \rho \theta(t)-\Delta \rho_{\chi},
$$

corresponding to an effective temperature contrast

$$
\theta_{\mathrm{eff}}=\frac{\Delta \rho_{\mathrm{eff}}}{\alpha \rho}=\left(\frac{B}{B_{c}}-B\right) \Delta T \sim(0.02 \pm 0.12) \times B \Delta T
$$

using equation (12). Only this thermal buoyancy is effectively available for driving motions: after the first destabilization, further rising and sinking of domes correspond to its gain and loss, whereas the "internal" temperature field $B \Delta T$, linked to the chemical field, remains stable [see also Herrick and Parmentier, 1994]. This explains why large temperature variations are measured over the whole tank depth, in contrast to classical RayleighBénard convection where thermal fluctuations are limited to thermal boundary layers (see Figure 6). It also explains why fluids with temperature-dependent viscosity give results similar to fluids with composition-dependent viscosity, when taking as viscosity ratio $\gamma$ the contrast due to the temperature jump $B \Delta T$ (see, for instance, Figure 7).

[21] One must notice that there is a huge difference between the total thermal anomaly and the thermal anomaly effectively available for buoyancy: as shown in Figure 8, taking typical values $\Delta T=2000 \mathrm{~K}$ and $\alpha=3 \times 10^{-5} \mathrm{~K}^{-1}$, a $1 \%$ density contrast implies

$$
\begin{gathered}
\theta=340 \pm 40 \mathrm{~K} \\
\theta_{\text {eff }}=6.7 \pm 40 \mathrm{~K} .
\end{gathered}
$$

In planetary mantles, estimation of temperature contrast derived from indirect measurements such as gravity [e.g., McNutt and Judge, 1990] are mostly dependent on the

Figure 6. Time evolution of the thermal signature of a two-layer experiment $\left(\gamma=15, a=0.30, R a=4.1 \times 10^{6}\right.$, initial $B=$ 0.80). (a) Temperature signals recorded along a vertical line. The location from the lower hot plate is reported on the right (initial interface position: $4.4 \mathrm{~cm}$ ). (b) Temperature signals recorded at two locations at midtank depth at $7 \mathrm{~cm}$ and $16.3 \mathrm{~cm}$ from the side. Both signals exhibit a time history in three parts: (1) the stratified phase, where purely thermal convection develops above and below the stable interface; (2) the whole layer phase, where the interface is destabilized and whole tank convection takes place; and (3) the final one-layer phase, where the interior of the tank is well mixed (classical RayleighBénard convection). (c-e) Corresponding standard deviations of the temperature signal measured along a vertical line. In the whole layer regime, the passage of a particle of fluid 1 anywhere in the tank differs from the passage of a particle of fluid 2 by $B \times \Delta T$, explaining the presence of large temperature variations over the whole depth. In the stratified regime, classical Rayleigh-Bénard convection takes place above and below the interface and after mixing, classical RayleighBénard convection takes place over the whole tank: temperature variations are then mostly limited to outer thermal boundary layers. 


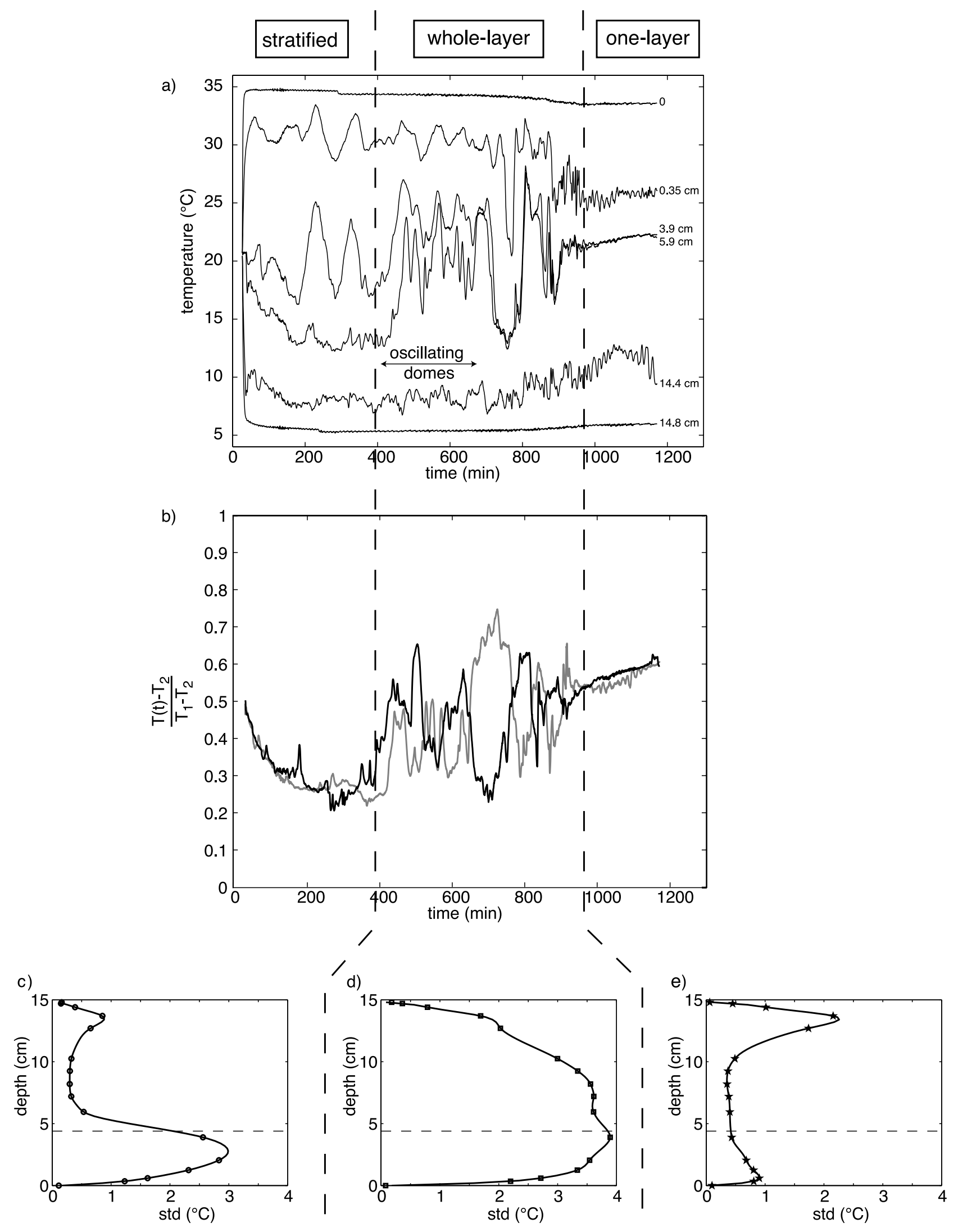

Figure 6. 
a)

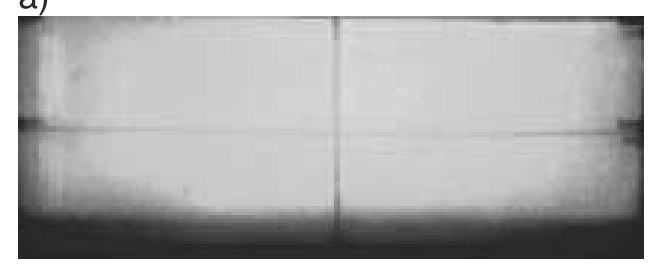

b)

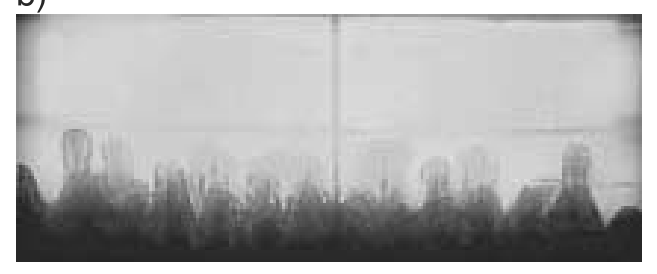

c)

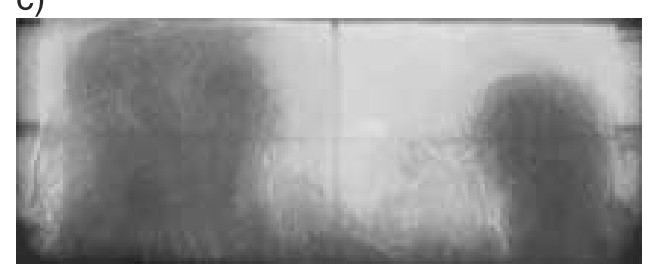

Figure 7. Time evolution of the experiment performed with liquid sugar DDC 131 from Béghin Say. This fluid exhibits a strong dependence on temperature. Even if no structural viscosity contrast is initially present in the tank, the temperature dependence of the viscosity induces a density jump across the interface $\gamma=0.18$ corresponding to the temperature jump $\theta$ given by equation (14). Other dimensionless numbers are $a=0.155, R a=3.0 \times 10^{7}$, and $B=0.30$. (a) Initial configuration, $t=0 \mathrm{~min}$. (b) Purely thermal convection, $t=2 \mathrm{~min}$, in the lower layer that partially penetrates the upper layer (i.e., dynamic topography). (c) Destabilization, $t=4 \mathrm{~min}$, of the lower layer under the form of large cavity plumes. See color version of this figure in the HTML.

effective thermal contrast, and must therefore be used with caution.

\subsection{Viscous Control on Thermochemical Structures}

[22] The characteristics of domes in both directions are mainly controlled by the most viscous layer, which slows down motions over the whole depth of the tank [Whitehead and Luther, 1975; Olson and Singer, 1985; Herrick and Parmentier, 1994].

[23] Diameter of the thermochemical structures can be calculated using the following scaling laws defined experimentally [Le Bars and Davaille, 2004]:

Case of diapiric plumes

$$
\frac{d_{\mathrm{dia}}}{H}=4.55 \frac{h_{\mathrm{mv}}}{H} R a_{\mathrm{mv}}^{-0.14},
$$

where the subscript mv stands for the most viscous fluid. Case of cavity plumes

$$
\frac{d_{\mathrm{cav}}}{H}=5.4 \frac{\left(h_{\mathrm{lv}} h_{\mathrm{mv}}^{2}\right)^{1 / 3}}{H} R a_{\mathrm{mv}}^{-0.093},
$$

where the subscript lv stands for the less viscous fluid.

[24] In both cases, we must notice that purely thermal convection inside each layer and thermochemical convection between both layers act on totally different length scales: in particular, when purely thermal plumes exist in the layer before doming, each dome collects several smallscale instabilities.

[25] Periods of pulsations are also controlled by the most viscous layer and scale as

$$
\tau=\frac{h_{\mathrm{mv}}^{2}}{\pi \kappa}\left(\frac{880}{R a_{\mathrm{mv}}}\right)^{2 / 3},
$$

where the coefficient 880 has been determined experimentally [Le Bars and Davaille, 2004]. Figures 9 and 10 show the typical variations of domes diameter and period with the viscosity ratio, the layer depth ratio and the Rayleigh number. Using equation (5), one can notice that

$$
\tau \sim \frac{1}{\pi \kappa}\left(\frac{1760 \kappa \nu_{\mathrm{mv}}}{\alpha g \Delta T}\right)^{2 / 3},
$$

which illustrates that $\tau$ is independent of layer depths.

[26] Since inertial effects are negligible, the typical domes velocity is given by the equilibrium between buoyancy effects and viscous dragging forces in the most viscous fluid:

$$
w=\frac{\Delta \rho_{\mathrm{eff}} g d^{2}}{32 \eta_{\mathrm{mv}}},
$$

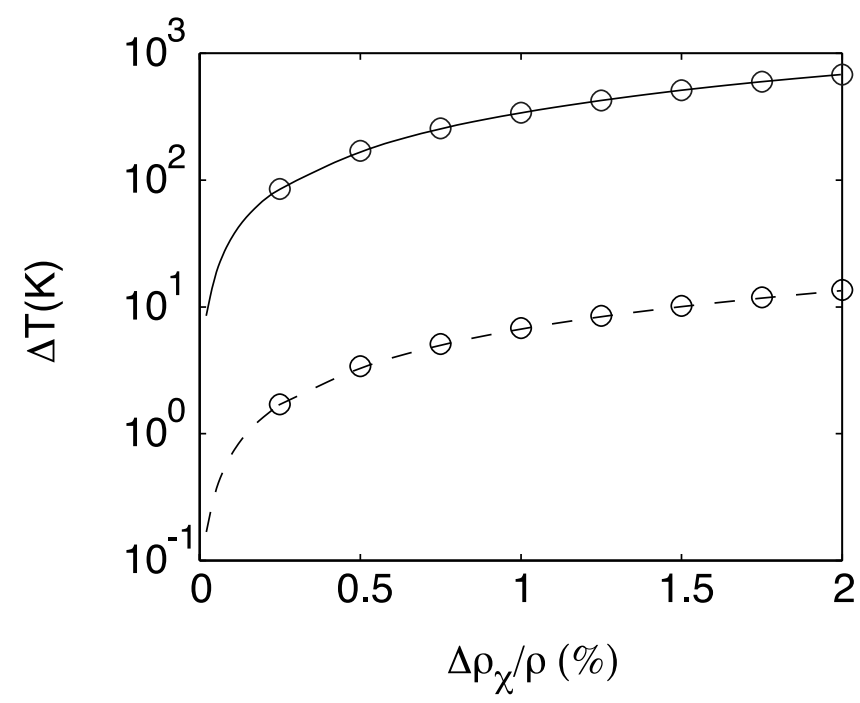

Figure 8. Total temperature anomaly (solid line with circles) and effective temperature anomaly (dashed line with circles) as a function of the chemical density contrast for a pulsating dome, taking $\Delta T=2000 \mathrm{~K}$ and $\alpha=3 \times 10^{-5} \mathrm{~K}^{-1}$. 
a)

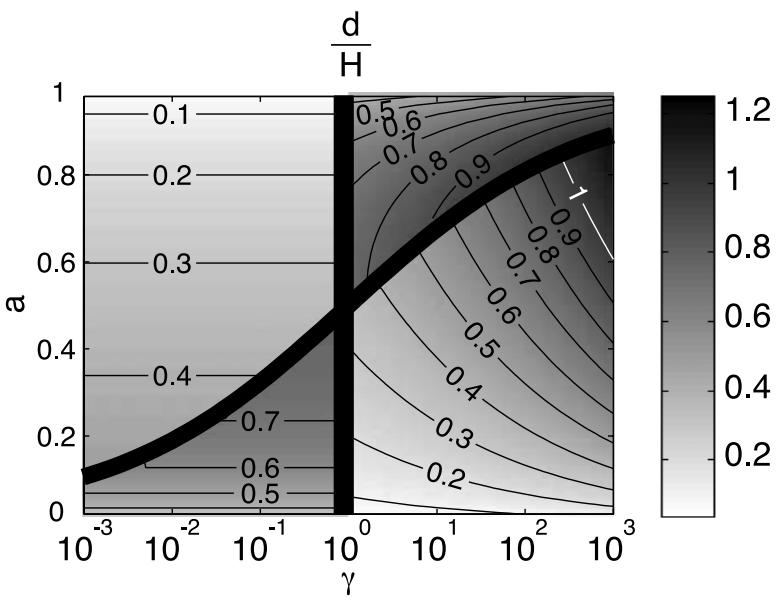

b)

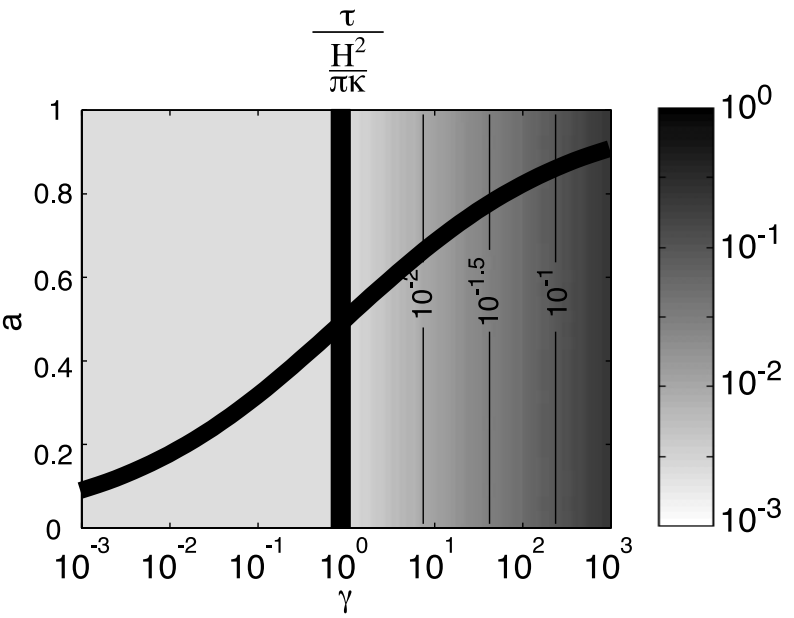

Figure 9. (a) Nondimensional diameter and (b) nondimensional period of thermochemical structures in planetary mantle as a function of the viscosity ratio $\gamma$ and the layer depth ratio $a$, taking a Rayleigh number $R a=1.3 \times 10^{7}$. Thick black lines indicate changes in the shape of thermochemical domes, as explained in section 2.1 and in Figure 3 .

where the scaling factor 32 has been determined experimentally [Le Bars and Davaille, 2004]. The $d$ designates the typical size of the dome $\left(d_{\mathrm{cav}}\right.$ or $\left.d_{\mathrm{dia}}\right), \eta_{\mathrm{mv}}$ the dynamic viscosity, and $\Delta \rho_{\text {eff }}$ the density contrast available for motion over the whole depth as given by equation (15), taking into account both thermal and chemical effects. In the case of diapiric plumes, the deformation takes the form of a vertical cylinder with a nearly constant diameter and the characteristic length that must be used in equation (23) is intermediate between the height of the plume $h$ and $d_{\text {dia }}$ : the rising speed progressively increases with $h$, and equation (23) only indicates a lower bound corresponding to the initial velocity.

[27] Using scaling laws previously defined, one can also estimate the heat flux transported by a thermochemical dome as

$$
Q=\rho C_{p} \theta \times \pi(d / 2)^{2} \times w,
$$

where $C_{p}$ is the specific heat per unit mass and $\theta$ the thermal excess given by equation (14).

\subsection{Time Evolution: From Whole Layer to One-Layer Convection}

[28] Because of entrainment and mixing, the whole layer regime systematically evolves toward single layer convection, as shown on Figures $1 \mathrm{f}-1 \mathrm{k}$. The mixing pattern is complicated, and advection creates compositional heterogeneities with two different typical sizes and topologies: (1) large-scale blobs can be encapsulated during domes oscillations (Figure 1i), and (2) thin filaments are generated by mechanical entrainment through viscous coupling (Figure 1j). Ultimately, chemical diffusion acts to fully homogenize the system. It is interesting to note that since the temperature field follows the chemical field and the viscosity is either temperature- or composition-dependent, viscosity structures are also strongly spatially variable and

a)

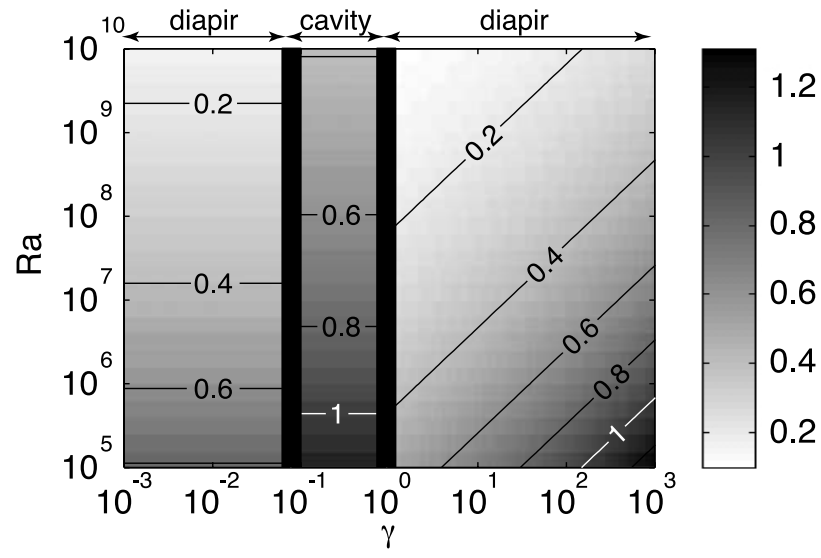

b)

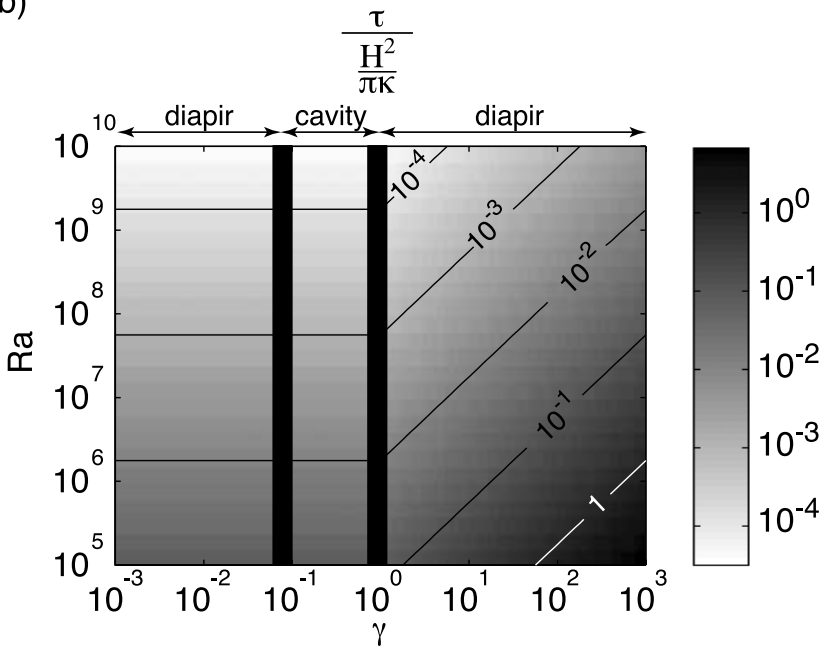

Figure 10. (a) Nondimensional diameter and (b) nondimensional period of thermochemical structures in planetary mantle as a function of the viscosity ratio $\gamma$ and the Rayleigh number $R a$, taking a layer depth ratio $a=0.3$. Thick black lines indicate changes in the shape of thermochemical domes, as explained in section 2.1 and in Figure 3. 
a)

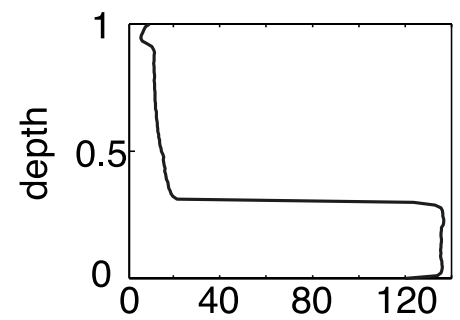

b)

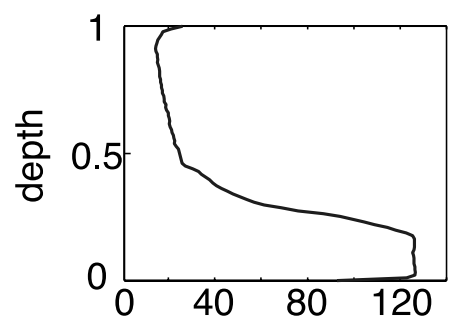

c)

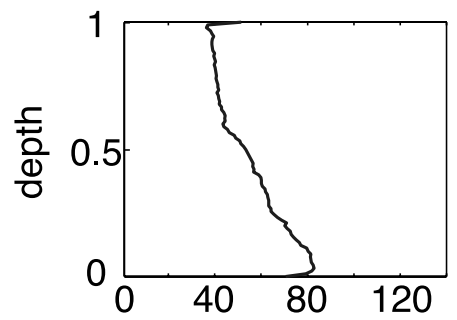

d)

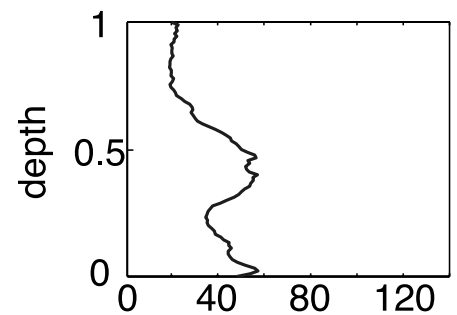

e)

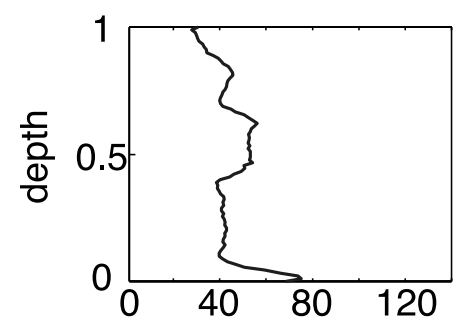

f)

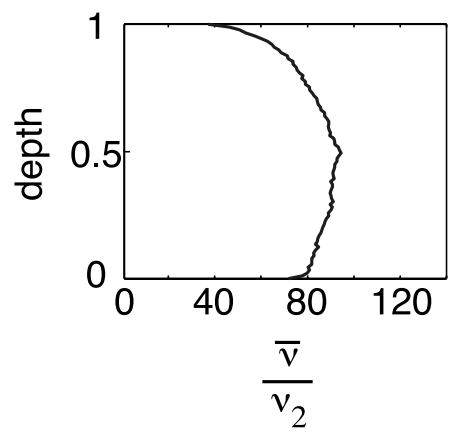

can not be deduced from the mean lateral value, as illustrated in Figures 11a-11f.

[29] The overall duration of thermochemical heterogeneities in the whole layer regime is very difficult to determine, since all dimensionless numbers directly influence it: the buoyancy number actually controls the "chemical" resistance to stirring, the viscosity ratio the "mechanical" resistance to stirring, the layer depth ratio the relative volume of heterogeneities and the Rayleigh number the convective stirring power. Studying the variation of the overall duration with all dimensionless numbers is beyond the scope of this paper. Moreover, with our experimental setting, only the buoyancy number can be changed independently of all other parameters: as shown in Figure 12, the overall duration then exhibits a strong exponential dependence on $B$, and the chemical heterogeneities can persist for very long time compared to the characteristics of thermal convection.

\section{Geological Consequences of Whole Layer Convection}

\subsection{Superplumes on Earth}

\subsubsection{Case Study of the Last Pacific Pulsation}

[30] The mantle beneath the Pacific plate seems to be confined in a simple natural tank: during the last $150 \mathrm{Myr}$, it has been isolated from the rest of the mantle by its subduction belt [Richards and Engebretson, 1992], and no continent has perturbed its upper thermal boundary. It is thus the best place for us to apply the scaling laws defined in section 2. One must, however, notice that this analogy is only a very simplified view of the effects of plate tectonics that allows us to directly applied the experimental results. The complications due to plate motions will be further discussed in section 4.6. The "Pacific superswell" [McNutt and Fisher, 1987] is a huge zone of Earth's surface about $5000 \mathrm{~km}$ large located in the south central Pacific, characterized by a concentration of intraplate volcanism and by an elevated topography, as much as $1 \mathrm{~km}$ higher than usual seafloor of the same age [McNutt, 1998]. The mantle located below it exhibits anomalous slow shear and compressional waves velocities all the way down to the coremantle boundary [Dziewonski and Woodhouse, 1987; Li and Romanowicz, 1996; Grand et al., 1997; Van der Hilst et al., 1997]: it has thus been suggested that the Pacific superswell is due to the dynamic upwelling of a large body called "superplume" [Larson, 1991; Cazenave and Thoraval, 1994], which may be stopped by the 660-km phase transition [Vinnik et al., 1997]. Such a structure is too large to be explained by instabilities in the framework of classical Rayleigh-Bénard convection. Besides, modeling based on tomography and geoid [Ishii and Tromp, 1999] or tomography and mineralogy [Yuen et al., 1993] further demonstrate that thermal effects alone can not explain the entire geophysical evidence: they must be coupled with a chemical

Figure 11. Vertical viscosity profiles averaged laterally corresponding to experiment pictures on Figures $1 \mathrm{f}-1 \mathrm{k}$. Viscosity structures cannot be deduced from the mean values. In the Earth, the presence of very viscous subducting plates complicates the situation. 


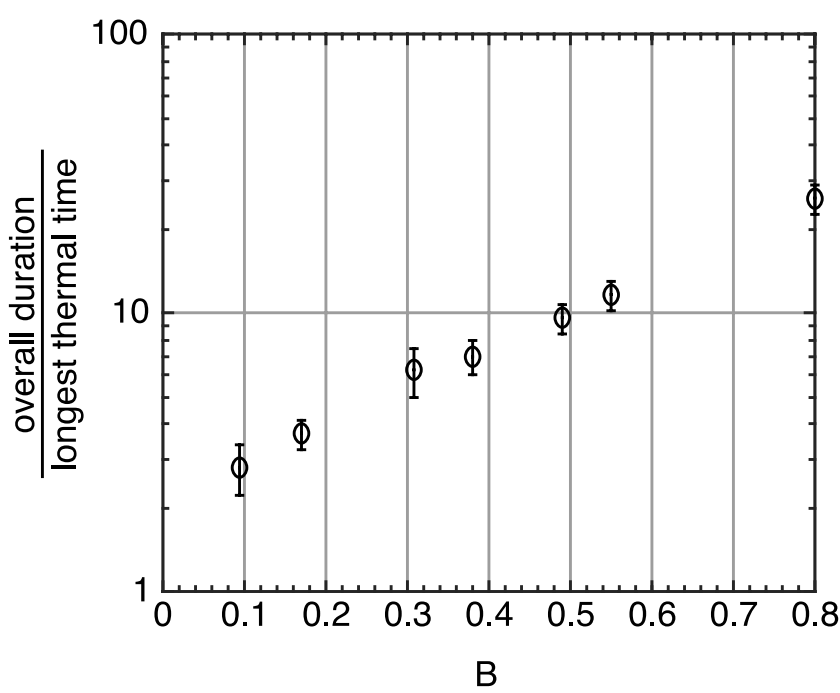

Figure 12. Overall duration of chemical heterogeneities measured experimentally, normalized by the typical convective time in the most viscous layer, which corresponds to the longest characteristic time of purely thermal effects in the system. In these experiments, only the buoyancy number $B$ significantly changes $(\gamma=8-22, a=0.25-$ $0.30, R a=4.1 \times 10^{6}$ to $\left.1.5 \times 10^{7}\right)$.

stratification. Another region now located on the west, the "Darwin Rise," registered similar characteristics 11090 Myr ago [Ménard, 1964; Winterer et al., 1993]. Plate reconstruction demonstrates that it was then passing above the present-day superswell. The "Pacific tank" has thus registered during the last $100 \mathrm{Myr}$ a complete pulsation of the mantle [Larson, 1991].

[31] Looking at all these features, Davaille [1999b] suggested that a superplume originates from the pulsatory behavior of thermochemical convection. Using the experimental results from section 2, we are now able to quantify this statement, taking as a working hypothesis that the lower mantle contains two chemically distinct reservoirs (lower layer 1 and upper layer 2) presently in the pulsating regime. Fixed parameters used in this study are listed in Table 2; the viscosity of the lower layer (hence the viscosity ratio $\gamma$ ) and the depth of each layer (hence the depth ratio a) are unknown and will be constrained by experimental results.

[32] Taking into account the uncertainty on Earth's data, errors on scaling laws, and also the extreme simplicity of our analogical model, we expect to predict the relevant orders of magnitude as far as the period of pulsations and the diameter of thermochemical structures are concerned, i.e.,

$$
\begin{gathered}
\tau=50-200 \mathrm{Myr} \Leftrightarrow \frac{\tau}{H^{2} / \pi \kappa}=10^{-3}-4 \times 10^{-3} \\
d=1000-3000 \mathrm{~km} \Leftrightarrow \frac{d}{H}=0.45-1.4 .
\end{gathered}
$$

Then, lots of couples $(\gamma, a)$ seem to be relevant for the mantle (see Figure 9). Additional constraints are given by (1) the spouting direction (i.e., from the bottom toward the surface) and (2) the occurrence of at least two successive pulsations in the Pacific: according to our experimental study, a viscosity contrast $>5$ or $<1 / 5$ is therefore necessary. The formation of a cavity plume then seems to be the most probable, with

$$
\begin{aligned}
& 10^{-2}<\gamma<1 / 5 \\
& 0.2<a<0.37 .
\end{aligned}
$$

These values are plausible in the Earth and are compatible with independent considerations from mineralogy and geochemistry. Indeed, the lower reservoir is chemically denser and possibly radiogenically enriched [Staudigel et al., 1991]: at a given depth, it is thus hotter than the upper layer. According to the temperature dependence of the viscosity [Karato and $W u, 1993$ ] and independently of any structural effects, the viscosity ratio is expected to be smaller than 1, in agreement with equation (27). Besides, results from equation (28) correspond to an initial lower reservoir thickness (i.e., before destabilization) ranging between 440 and $810 \mathrm{~km}$. These values are in the lower bound of the predicted size of the geochemical "undepleted" reservoir, which occupies between 10\% [Hofmann, 1997] and 75\% [Jacobsen and Wasserburg, 1979] of the whole mantle, corresponding to a thickness between 516 and $2420 \mathrm{~km}$. However, our predicted value only corresponds to the last pulsation of the Pacific: the size of the reservoir (as well as the viscosity ratio) may have been larger in the past and have since evolved because of mixing. Such variations have to be taken into account in geochemical studies to allow better comparisons.

\subsubsection{African Uplift}

[33] A second superswell is located in Africa and South Atlantic Ocean [Nyblade and Robinson, 1994]. As for the Pacific superswell, it has been explained by the dynamical upwelling of a hot and very large structure [Lithgow-Bertelloni and Silver, 1998], and high-resolution tomographic inversions have imaged the presence of a superplume about $1200 \mathrm{~km}$ across with very sharp interfaces, extending obliquely $1500 \mathrm{~km}$ upward from the core-mantle boundary [Ritsema et al., 1998; Ni et al., 2002].

[34] Gurnis et al. [2000] have recently developed a dynamical model relating a superplume type motion to the surface residual topography (i.e., after shallow sources of density have been removed) and to the average uplift rate registered in southern Africa. They concluded that (1) a small global density contrast is needed to explain the present elevation of 300-600 $\mathrm{m}$ and (2) a low viscosity

Table 2. Typical Values Used for Earth's Lower Mantle With $R a=1.3 \times 10^{7}$ and $B=0.17$

\begin{tabular}{ll}
\hline Parameter & \multicolumn{1}{c}{ Value } \\
\hline$H$ & $2200 \mathrm{~km}$ \\
$\rho_{20}$ & $4100 \mathrm{~kg} \mathrm{~m}^{-3}$ \\
$\Delta T$ & $2000 \mathrm{~K}$ \\
$\alpha$ & $3 \times 10^{-5} \mathrm{~K}^{-1}$ \\
$\kappa$ & $10^{-6} \mathrm{~m}^{2} \mathrm{~s}^{-1}$ \\
$\eta_{2}$ & $2 \times 10^{21} \mathrm{~Pa} \mathrm{~s}$ \\
$\Delta \rho_{\chi} / \rho$ & $1 \%$ \\
\hline
\end{tabular}


Table 3. Derivatives of Bulk Modulus, Shear Modulus, and Density for Pure Perovskite and Pure Magnesiowüstite ${ }^{\mathrm{a}}$

\begin{tabular}{lcc}
\hline & perovskite & magnesiowüstite \\
\hline$K_{0}, \mathrm{GPa}$ & 258.1 & 161.0 \\
$\partial K / d T, \mathrm{GPa}$ & -0.031 & -0.028 \\
$\partial K / d P$ & $4.1 \times 10^{-9}$ & $4.1 \times 10^{-9}$ \\
$\partial K / d x_{\mathrm{Fe}}, \mathrm{GPa}$ & 0 & 7.5 \\
$\mu_{0}, \mathrm{GPa}$ & 176.8 & 131.0 \\
$\partial \mu / d T, \mathrm{GPa}$ & -0.019 & -0.024 \\
$\partial \mu / d P$ & $1.4 \times 10^{-9}$ & $2.4 \times 10^{-9}$ \\
$\partial \mu / d x_{\mathrm{Fe}}, \mathrm{GPa}$ & small (taken 0$)$ & 77.0 \\
$\rho_{0}, \mathrm{~kg} \mathrm{~m}^{-3}$ & 4108 & 3583 \\
$\partial \rho / d x_{\mathrm{Fe}}, \mathrm{kg} \mathrm{m}^{-3}$ & 1070 & 2280 \\
\hline
\end{tabular}

${ }^{\mathrm{a}}$ Proposed by Samuel and Farnetani [2001] (temperature and pressure dependence from Matsui [2000] and Matsui et al. [2000]; iron dependence from Wang and Weidner [1996, and references therein]). Subscript zero means surface temperature, surface pressure, and $x_{\mathrm{Fe}}=0$. For the calculations of velocity anomalies, we use the hydrostatic pressure, the adiabatic temperature gradient and a constant $\alpha=3 \times 10^{-5} \mathrm{~K}^{-1}$.

inside the hot structure, which could be explained by the temperature dependence of the viscosity [Karato and $W u$, 1993], is needed to account for the measured uplift rate of 5-30 $\mathrm{m} \mathrm{Myr}^{-1}$.

[35] Their results are thus qualitatively similar to ours. Quantitatively, they were able to satisfy Earth's constraints with $\Delta \rho_{\text {eff }} \rho \sim 0.2 \%$ and $\eta_{1} \sim 10^{21}-10^{22}$ Pa s. For a chemical density contrast of $1 \%$ and using values determined in the Pacific (see section 3.1.1), we propose $\Delta \rho_{\text {eff }} / \rho \sim 0.02 \%$ and $\eta_{1} \sim 10^{20} \mathrm{~Pa}$ s. However, according to their study, a tenfold decrease in the density anomaly leads to a tenfold decrease in topography and a hundredfold decrease in uplift rate, and a tenfold to hundredfold decrease in the lower mantle viscosity leads to a threefold to tenfold increase in topography and a tenfold to hundredfold increase in uplift rate: both effects thus compensate and our preferred values could also fit the African case well.

\subsubsection{Seismic Velocity Anomalies}

[36] In order to better compare our results with Earth's data, it is possible to convert the chemical and thermal signals associated with an oscillating dome into shear waves, compressional waves, and bulk sound velocities given by

$$
\begin{gathered}
V_{s}=\sqrt{\frac{\mu}{\rho},} \\
V_{p}=\sqrt{\frac{K+(4 / 3) \mu}{\rho},} \\
V_{\phi}=\sqrt{\frac{K}{\rho},}
\end{gathered}
$$

respectively, where $K$ and $\mu$ are the bulk and the shear modulus.

[37] Following Forte and Mitrovica [2001] and Samuel and Farnetani [2001], we only take into account two phases in the lower mantle: perovskite $(\mathrm{Mg}, \mathrm{Fe}) \mathrm{SiO}_{3}$ and magnesiowüstite $(\mathrm{Mg}, \mathrm{Fe}) \mathrm{O}$. Chemical density variations between the two reservoirs are due to changes in iron molar ratio $x_{\mathrm{Fe}}=\mathrm{Fe} /(\mathrm{Fe}+\mathrm{Mg})$ and/or in volumic proportion of perovskite $(\Phi)$ and magnesiowüstite $(1-\Phi)$. We suppose the upper reservoir to have a pyrolitic composition, corresponding to reference coefficients $x_{\mathrm{Fe}}=0.11$ and $\Phi=$ 0.82 [Guyot et al., 1988]. The chemical density excess of the lower layer $\Delta \rho_{\chi}$ is then converted either in change in iron molar ratio for a fixed volumic proportion of perovskite or in change in volumic proportion of perovskite for a fixed iron molar ratio. In the whole system regime, this stratification is compensated by a mean temperature excess $\theta$ given by equation (14), which we first suppose to apply to the whole lower reservoir. Bulk modulus and shear modulus are then calculated inside each layer for pure perovskite and pure magnesiowüstite using the derivative coefficients from Samuel and Farnetani [2001] (Table 3), and seismic velocities are finally estimated inside each reservoir using a Voigt-Reuss-Hill average. To remain consistent with experiments, we only consider here a constant thermal expansion coefficient $\alpha=3 \times 10^{-5} \mathrm{~K}^{-1}$ through the whole lower mantle.

[38] Results for three different models are presented in Figure 13. We can first notice that all of them give relevant orders of magnitude as far as velocity anomalies are concerned, with typical amplitude between $-3 \%$ and $1 \%$. However, only variations of the volumic proportion of perovskite as shown in Figures 13a and 13c are capable of reproducing two striking features observed by recent seismic studies of the deep lower mantle under superswells, namely, (1) a large ratio of shear to compressional waves velocity anomalies [Roberston and Woodhouse, 1996] and (2) an anticorrelation between shear waves and bulk sound velocity anomalies [Su and Dziewonski, 1997; Ishii and Tromp, 1999]. Changes in iron molar ratio alone do not give such characteristics (Figure 13b).

[39] Figure 14 shows the tomographic signal obtained with our method from Figure 1i scaled to the mantle, for a chemical density contrast of $1 \%$. Results can be filtered to take into account the resolution of Earth's tomography, typically $400 \mathrm{~km}$ in the horizontal direction and $200 \mathrm{~km}$ in the vertical direction: the complex pattern of thermochemical structures is then partially erased and only the two major upwellings persist, which could represent for instance the Pacific and African superswells.

[40] Those results correspond to an "average" point of view, supposing all points in the lower layer have the same temperature excess given by equation (14). However, equation (14) only indicates a mean value over the whole system at the time of destabilization: locally, the real temperature contrast can be larger, as for instance in the upper part of the rising dome, or smaller, as for instance in its lower part. Figure 15 then shows the relative variations of the predicted seismic anomaly: in the African superswell, this could explain the simultaneous detection of a stratified root [Ishii and Tromp, 1999] and a buoyant head [Ritsema et al., 1998]. One must also notice that part of the thermochemical structures can be hidden from seismic detection by the local compensation of thermal and chemical effects: tomographic inversions may underestimate the real extension of superplumes. The small amplitude of the predicted anomaly as well as the expected highly distorted interface could explain why Vidale et al. [2001] did not locate any thermochemical boundary despite a precise search. 
a)

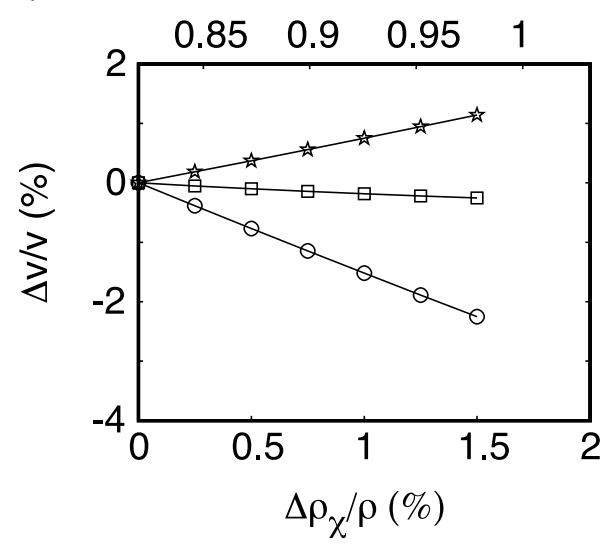

c)

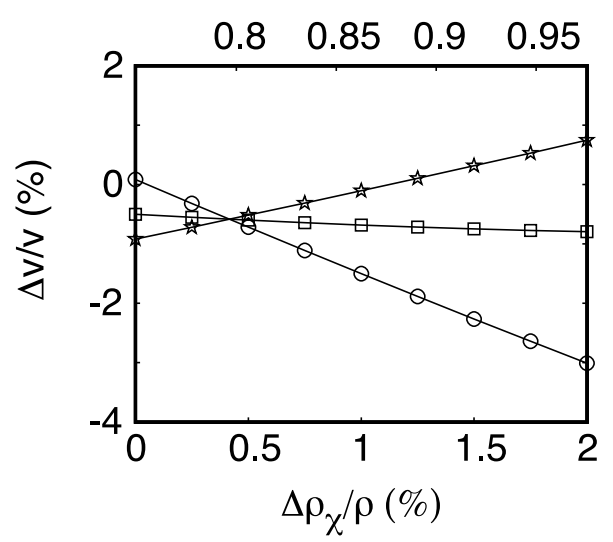

b)

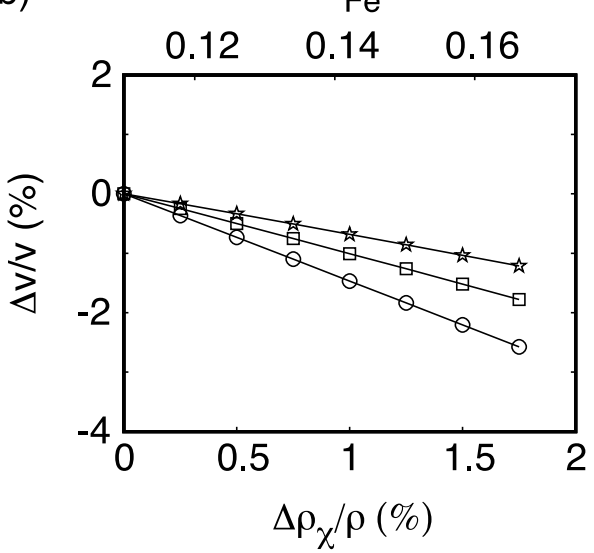

Figure 13. Variations of the velocity anomalies at the midmantle depth as a function of the chemical density contrast for a pulsating dome (circles, shear waves; squares, compressional waves; stars, bulk sound). In all cases, the upper reservoir is supposed to have a pyrolitic composition, corresponding to iron molar fraction $x_{\mathrm{Fe}}=0.11$ and volumic proportion of perovskite $\Phi=0.82$ [Guyot et al., 1988]. Density contrast comes from changes in the lower reservoir: (a) $x_{\mathrm{Fe}}=0.11$ and density contrast comes from changes in $\Phi$ (top scale); (b) $\Phi=0.82$ and density contrast comes from changes in $x_{\mathrm{Fe}}$ (top scale); (c) $x_{\mathrm{Fe}}=0.13$ and density contrast comes from changes in $\Phi$ (top scale).

[41] Thermochemical doming thus provides a plausible explanation, both qualitatively and quantitatively, for the superswells observed at present on Earth's surface and for the underlying superplumes imaged by tomography. Further work is now needed to see if these dynamical features could also account for coinciding patterns in geoid [Cazenave et al., 1989] and in the anomalous flattening of the CMB inferred from geodetic estimates of Earth's free core nutation [Forte et al., 1995].

\subsection{Pulsations on Earth}

[42] We will now go further in the past and see to what extent previous pulsations of thermochemical plumes can be related to changes at global scale observed in the geological record.

[43] Since its formation, the Earth has undergone gradual cooling, but this global decline has been interrupted by periods of enhanced convective vigor and surface heat flow (see for instance the recent review by Schubert et al. [2001, pp. 626-627]. Several mechanisms have already been identified that could create such episodicity. First, convec- tion at high Rayleigh number is by essence episodic, generating thermal plumes: the arrival of such features at the surface could then account for the creation of major flood basalt events [Richards et al., 1989; White and McKenzie, 1989]. On a larger scale, Wilson cycles [Wilson, 1966] corresponding to the periodic fragmentation and reformation of supercontinents could be link to the temporal variability in plate tectonics. Numerous studies have also pointed out the effect of the $660-\mathrm{km}$ endothermic phase transition on convection: it could actually generate the periodic occurrence of abrupt changes in convective mode (660-km layered/whole mantle), consecutive with the sudden flushing of oceanic plates previously accumulated above the transition zone [Machetel and Weber, 1991; Tackley et al., 1993; Weinstein, 1993; Solheim and Peltier, 1994]. Such events have the potential to influence the mantle on a global scale [Weinstein, 1993; Brunet and Machetel, 1998]: the arrival of cold avalanche material at the CMB would actually significantly modify core heat flux, whereas in order to conserve mass, hot material from the lower mantle would rapidly be injected 
a)

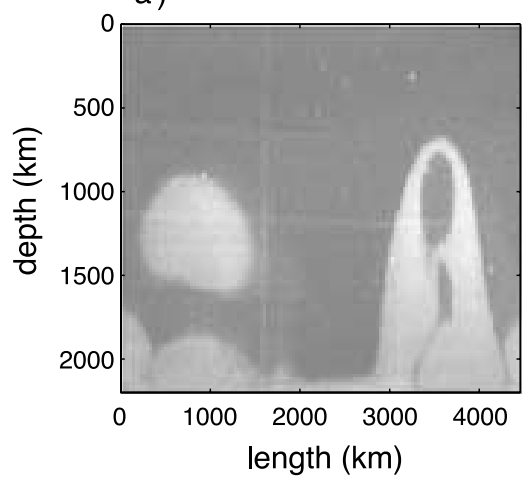

b)

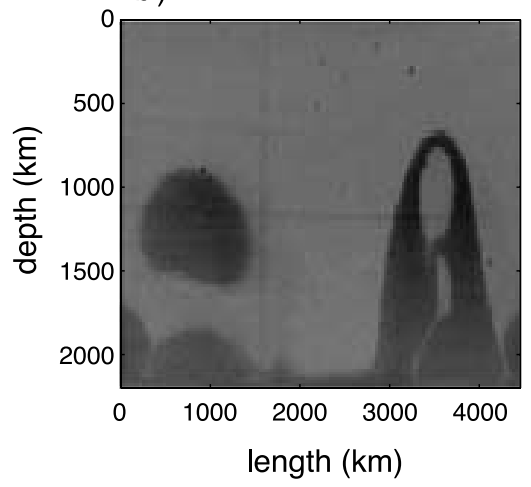

c)

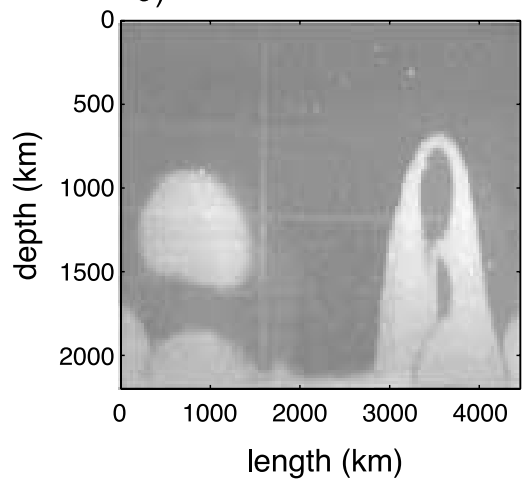

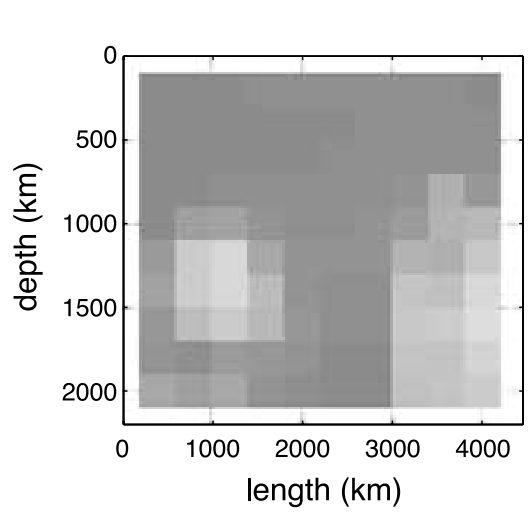

$\Delta \mathrm{v}_{\mathrm{s}} / \mathrm{v}(\%)$

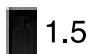

1

0.5

0

$-0.5$

$-1$

$-1.5$

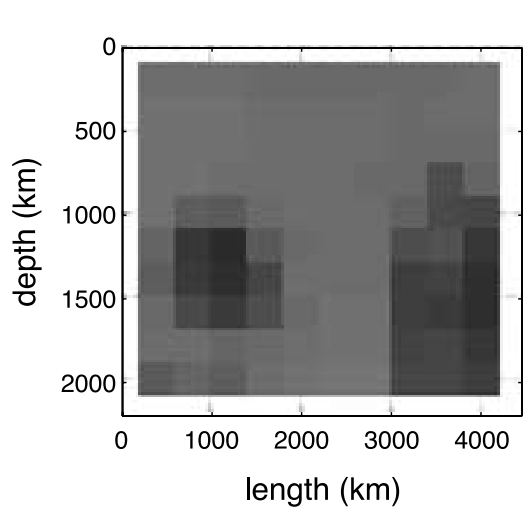

$\Delta \mathrm{v}_{\phi} / \mathrm{v}(\%)$

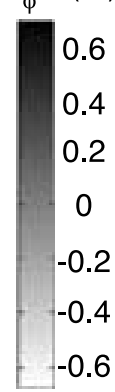

length $(\mathrm{km})$

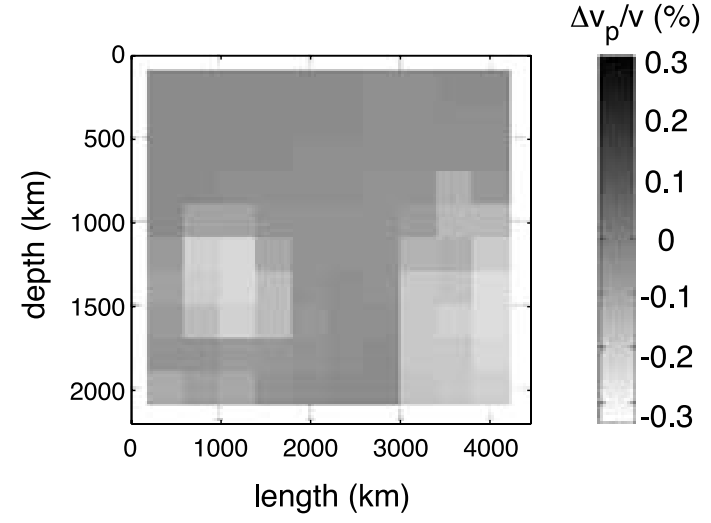

Figure 14. Tomography of Figure 1i, taking $x_{\mathrm{Fe}}=0.11, \Phi=0.82$ in the upper reservoir, $x_{\mathrm{Fe}}=0.11, \Phi=$ 0.93 in the lower reservoir (corresponding to $1 \%$ chemical density contrast), and a constant thermal expansion coefficient $\alpha=3 \times 10^{-5} \mathrm{~K}^{-1}$ (as for the experiments). (a) Shear waves, (b) bulk sound, and (c) compressional waves. (left) Direct results and (right) averaged signal through $400 \times 200 \mathrm{~km}$ cells, comparable to typical Earth's models resolution.

into the upper mantle with attendant thermal consequences at the surface.

[44] Pulsations in our analogical experiments provide another simple explanation for episodicity at a global scale. As a matter of fact, the amplitude of the heat flux perturbation associated with a dome has the same order of magnitude as the average heat flux out of the thermal boundary layers [Le Bars and Davaille, 2004]. An important part of thermal transfers is thus attached to the pulsations of thermochemical structures. Figure 16 presents the typical variations with the chemical stratification of the rising velocity $w$ given by equation (23), and of the estimated associated heat flux $Q$ given by equation (24). A
$1 \%$ density contrast implies (1) a velocity of $8 \mathrm{~cm} \mathrm{yr}^{-1}$, in good agreement with typical velocities given by plate tectonics and (2) a heat flux of $3 \times 10^{13} \mathrm{~W}$, comparable to the total heat flux escaping from the Earth $\left(Q_{\text {surface }} \sim 4 \times\right.$ $10^{13} \mathrm{~W}$ [Poirier, 1991]), and even larger than the estimated flux at the base of the mantle $\left(Q_{\text {core }} \sim 4 \times 10^{12} \mathrm{~W}\right.$ [Poirier, 1991]).

[45] Earth's thermal history may have been punctuated by great variations corresponding to thermochemical pulsations, and current estimations of evacuated heat may largely underestimate the reality [see also Romanowicz and Gung, 2002]. Besides, such pulsations can be qualitatively and quantitatively related to large-scale geological conse- 

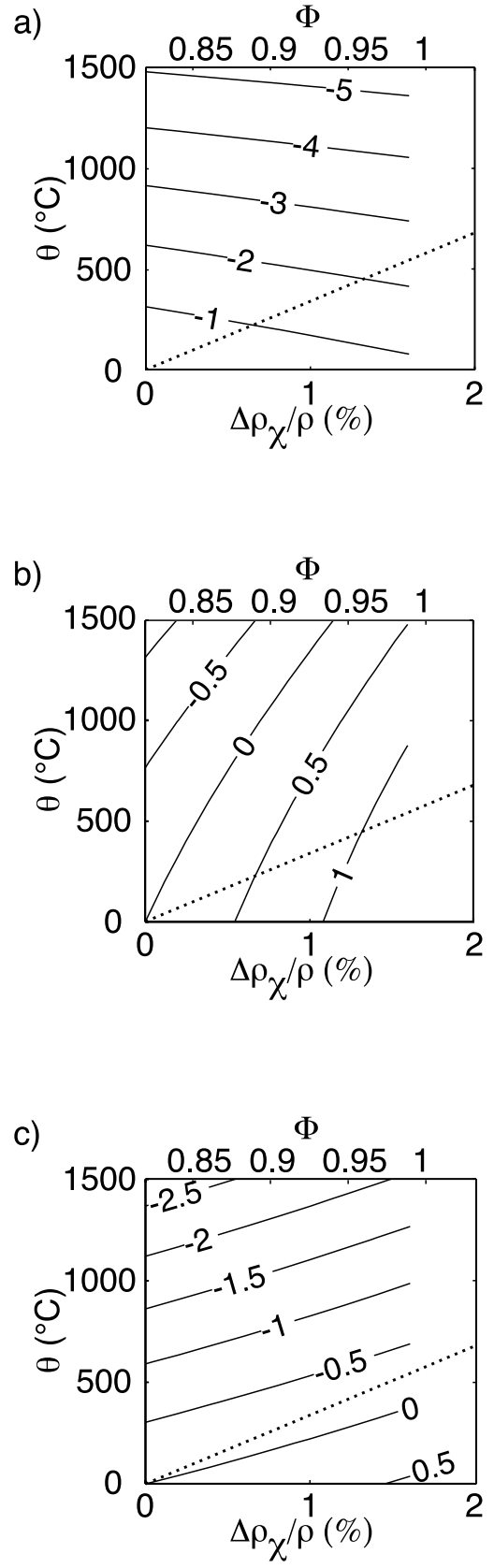

Figure 15. Predicted seismic anomaly in percent depending on the local temperature excess $\theta$ and the chemical density contrast $\Delta \rho_{\chi} / \rho$, taking $x_{\mathrm{Fe}}=0.11$ in both layers, $\Phi=$ 0.82 in the upper layer and a variable $\Phi$ in the lower layer (top scale): (a) shear waves, (b) bulk sound, and (c) compressional waves. Dotted lines show the "equilibrium" position, where thermal effects compensate for chemical stratification as given by the mean equation (14).

quences, particularly intense volcanism and modifications of magnetic field.

\subsubsection{Pulses of Surface Volcanism}

[46] The heat transported by a dome is typically 80 times larger than the estimated value for Hawaii, the current most powerful hot spot $\left(Q_{\text {Hawaii }} \sim 3.6 \times 10^{11} \mathrm{~W}\right.$ [Schubert et al. 2001]). We can thus expect each pulsation to have produced an intense volcanic activity at the surface. Such periods may be linked to various interrelated geological consequences through Earth's history, such as (Figure 17): (1) episodic formation of significant quantities of hydrocarbons and coal [Larson, 1991], as well as the emission of important volumes of $\mathrm{CO}_{2}$ [Caldeira and Rampino, 1991], (2) abundant deposits of iron [Isley and Abbott, 1999] and phosphate [Garzanti, 1993], (3) peak in the occurrence and diversity of stromatolites [Condie, 1998], (4) significant climatic modifications, with anoxic conditions and temperature variations [Larson, 1991; Caldeira and Rampino, 1991; Garzanti, 1993; Isley and Abbott, 1999; Ray and Pande, 1999], (5) mass extinctions [Courtillot and Besse, 1987; Courtillot et al., 1996; Ray and Pande, 1999], (6) pulses of oceanic and continental crust production [Larson, 1991; Stein and Hofmann, 1994; Condie, 1998], (7) rising of oceans level [Sheridan, 1983; Larson, 1991], and (8) initiation of major tectonic cycles, corresponding to the fragmentation and reformation of supercontinents [Sheridan, 1983; Courtillot and Besse, 1987; Condie, 1998].

[47] The best documented event took place in the Cretaceous, between 124 and 83 Myr [Larson, 1991]: it can be related to the formation of the Darwin Rise. Many other episodes are proposed, but do not receive general agreement, because lots of proofs are gradually erased from geological registers. For instance, Condie [2002] proposes pulsations at 280, 480, 1900, and $2700 \mathrm{Myr}$. Utsunomiya et al. [2002] suggest that the Pacific superswell was created during fragmentation of supercontinent Rodinia $750 \mathrm{Myr}$ ago, and then performed four pulsations (550-500 Myr, 300-250 Myr, 124-83 Myr and today); they also connect the first appearance of the African superswell with the fragmentation of Pangea $250 \mathrm{Myr}$ ago. Isley and Abbott [1999] propose a series of four pulses between 2750 and $2000 \mathrm{Myr}$, at regular intervals of $250 \mathrm{Myr}$.

\subsubsection{Influence of the Departure of a Dome on the Dynamo}

[48] The terrestrial magnetic field is due mainly to rapid convective motions in the liquid external core. Its

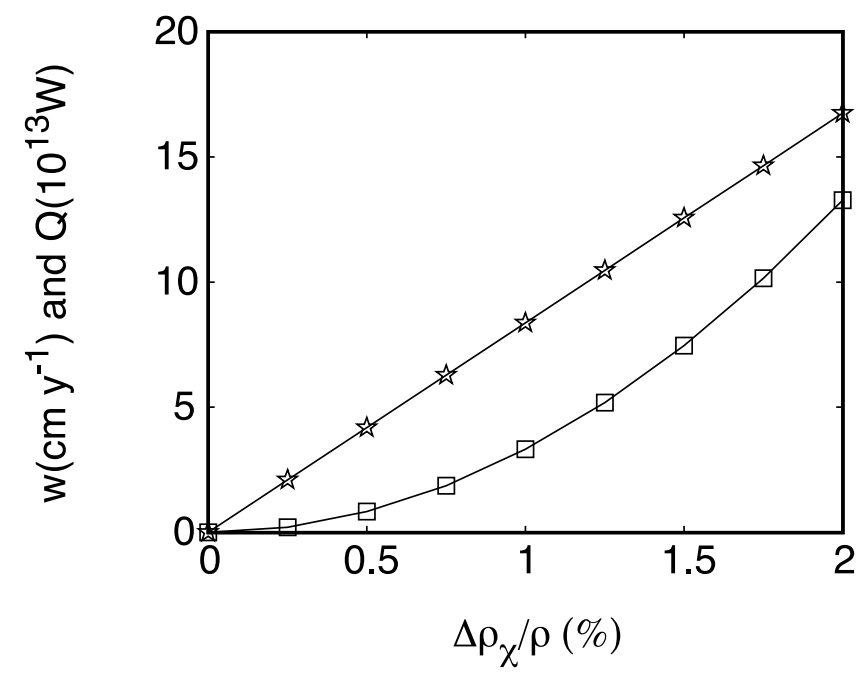

Figure 16. Typical rising velocity of a dome (stars) and associated heat flux (squares) as a function of the chemical stratification. 


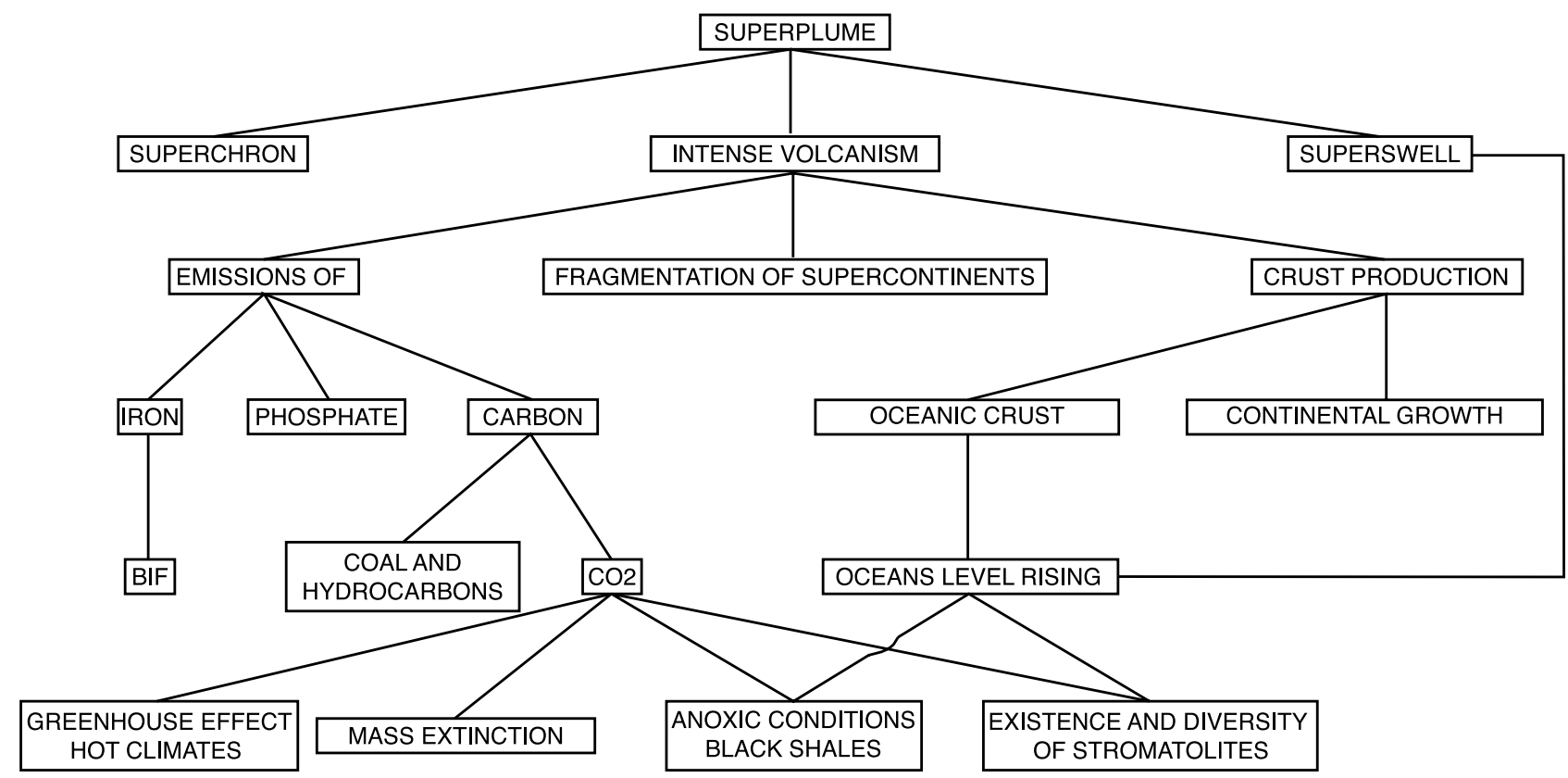

Figure 17. Possible geological consequences of thermochemical domes.

polarity has reversed several hundred times during the past 80 Myr. However, some periods without magnetic inversion during several tens of millions years are observed in Earth's history. Such superchrons [Cox, 1982] are too long to be accepted as part of the usual reversal process controlled by core dynamics: a lower mantle influence is thus expected [Courtillot and Besse, 1987; Larson and Olson, 1991; Merrill and McFadden, 1995]. The apparent correlation between superchrons and periods of strong volcanism described above [Sheridan, 1983; Courtillot and Besse, 1987; Larson, 1991] then reinforces a superplume model: the rising of such a giant thermochemical feature would cause a large temperature decrease at the core-mantle boundary, thus a strong increase in the heat gradient; the larger heat flux would then affect motions in the core, possibly stabilizing the dynamo [Larson and Olson, 1991]. The estimated heat flux from our dynamical model quantitatively agrees with these proposals.

[49] In addition to these temporal variations, the presentday antipodal Pacific and African superswells induce heterogeneous heat flow boundary conditions at the CMB that could account for the observed lateral variations of the geomagnetic field characteristics and for the asymmetric structure of the inner core [Sumita and Olson, 1999]. They could also be linked to the suggested occurrence of preferred pole paths near $90^{\circ} \mathrm{W}$ and $90^{\circ} \mathrm{E}$ longitudes during polarity reversals (see review by Gubbins [1994], but also Merrill and McFadden [1999]).

[50] These various phenomena are still controversial: rapid improvements in dynamo models will soon help to precisely test them. Besides, we do not claim that the rising of hot thermochemical domes is the only explanation for the various long-term and large-scale magnetic evidence: the sinking of cold structures, as for instance subducted plates in the alternative "flushing event" explanation presented above, could actually in- duce similar effects [Gallet and Hulot, 1997; Labrosse, 2002].

\subsection{Pulsations on Mars and Venus}

[51] The mantle of some terrestrial planets could also follow pulsatory dynamics [Herrick and Parmentier, 1994]. As far as Venus is concerned, the observation of meteorites impacts shows that the surface of this planet was entirely renewed 300-500 Myr ago in a very fast process $(<10-$ $50 \mathrm{Myr}$ ) [Strom et al., 1994]; since then, its volcanic and tectonic activities have been considerably reduced. The explanation for these observations thus demands a fast, intense and large-scale phenomenon: presuming a two-layer mantle, it could correspond to an abrupt draining of the lower or of the upper reservoir, such as we observed in experiments with small $B$ (Figures $5 \mathrm{f}, 5 \mathrm{~g}$, and $5 \mathrm{~h}$ ). The absence of rigid tectonic plates could explain the integral renewal of the surface, in contrast to Earth's superswells (Figures 5c, 5d, and 5e. Quantitative estimations of pulsations period can be derived from results presented in Figure 9b, taking $\alpha \sim 2 \times 10^{-5} \mathrm{~K}^{-1}, \rho \sim 5250 \mathrm{~kg} \mathrm{~m}^{-3}, g$ $\sim 8.6 \mathrm{~m} \mathrm{~s}^{-2}, \Delta T \sim 2000 \mathrm{~K}, H \sim 3000 \mathrm{~km}, \kappa \sim 10^{-6} \mathrm{~m}^{2} \mathrm{~s}^{-1}$, and $\eta_{2} \sim 10^{22}$ Pa s [Schubert et al., 2001]: for a less viscous lower reservoir $(\gamma<1)$, the period is controlled by the most viscous upper layer and the minimum of $420 \mathrm{Myr}$ is obtained; it can become much longer for a most viscous lower reservoir.

[52] The early evolution of Mars has been marked by episodes of violent and fast release of enormous quantities of water stored on the surface [Kargel and Strom, 1992], and right below the surface [Tanaka and Chapman, 1992]. These events could have been triggered by sudden increases in volcanic activity over large areas [Baker et al., 1991], which could be consecutive to thermochemical pulsations; the progressive stirring between the two reservoirs would then explain why these oscillations and the related volcanism have finally stopped 1 Gyr ago [Greeley and Schneid, 1991]. 
[53] The implications presented here are mainly speculative, and do not allow to choose between the superplume and the flushing event explanations. However, they point out that (1) the evolution of various planets exhibits major cycles of convective activity that can not be explained in the framework of classical Rayleigh-Bénard convection and (2) the simple assumption of a second reservoir can explain these various phenomena, while insisting on the evolutionary character of the convective regime.

\section{Discussion}

[54] Our experimental model precisely quantifies the effects of density and viscosity contrasts on the two-layer convection: it thus explains from a fluid dynamics point of view some key mechanisms taking place in the Earth. It is, however, impossible to build an experimental miniature mantle taking into account all natural complications: we will thus try to estimate their respective influence.

\subsection{Presence of the Continents}

[55] The continents at the surface of the Earth modify the upper thermal boundary conditions: within the framework of classical Rayleigh-Bénard convection, their presence results in focusing rising hot structures [e.g., Guillou and Jaupart, 1995]. One can thus imagine that this conclusion will remain essentially unchanged in the case of thermochemical structures. In particular, the presence of a "supercontinent" will encourage the formation of a great dome, whose energy will be sufficient to split it up, thus initiating a new tectonic cycle [Sheridan, 1983; Courtillot and Besse, 1987; Condie, 1998].

\subsection{Internal Heating}

[56] Mantle rocks are radiogenic, creating internal heat sources for convection. Besides, heat budgets require the lower reservoir to be presently radiogenically enriched [McKenzie and Richter, 1981; Kellogg et al., 1999]. Such a differentiated heating is not reproducible in our experiments. We can, however, estimate that it will have a twofold effect in the mantle. Inside one reservoir independently, the presence of internal heating will reduce the intensity of small-scale purely thermal regime: the effective Rayleigh number of a given layer actually scales as [McKenzie et al., 1974]

$$
R a_{\mathrm{eff}, i}=R a_{i}(1-r / 2)
$$

where $R a_{i}$ is the Rayleigh number for purely bottom heating and $r$ the ratio of the internal heat flux over the total heat flux. However, additional heat sources in the lower reservoir will increase its average temperature and thus the temperature difference between the two layers, which will tend to encourage destabilization. Since our results are based on a local approach taking into account local density, viscosity, and temperature contrasts around the interface, the critical values of the key parameter $B$ delimitating the different regimes as well as the physical description of their main characteristics will, however, remain valid.

\subsection{Variations of the Viscosity}

[57] The variations of viscosity inside the mantle are poorly known: in addition to the strong dependence on pressure and temperature [Karato and $W u, 1993$ ], one must take into account possible variations of structural origin, which are not constrained. Current models propose radial mean vertical profiles [e.g., Forte and Mitrovica, 2001], but these results are not usable within the framework of whole layer convection: as shown in Figure 11, large viscosity fluctuations can indeed be observed in the absence of planet-wide viscosity stratification, and the value of the viscosity contrast between layers can only be deduced from those fluctuations when the chemical field is also known.

[58] The dependence on pressure is not reproducible in the laboratory, but it probably has a weak influence on thermochemical structures since the relevant parameter for domes dynamics corresponds to the viscosity contrast at the interface between the two fluids, therefore at a given pressure. The dependence on temperature can be mimicked by sugar solutions: one experiment with liquid sugar "DDC 131" from Béghin Say has thus been performed (Figure 7). Since thermal anomalies in the whole layer regime are directly linked to the chemical composition (see section 2.2), this experiment exhibits results qualitatively and quantitatively similar to the other experiments with composition-dependent viscosity, taking for $\gamma$ the viscosity contrast at the interface.

\subsection{Variations of the Thermal Expansion Coefficient}

[59] The effective variations of the thermal expansion coefficient do not really influence the large-scale thermochemical regime, since only the average buoyancy force between layers is important (see discussion by Le Bars and Davaille [2004]). For instance, Hansen and Yuen [2000] claim that a buoyancy number of 0.5 is sufficient to stabilize the deep layer over Earth's history in their calculations. This value is calculated with surface properties: taking into account the decrease of $\alpha$ by a factor 3 within the mantle, it corresponds to a mean value $B_{\text {mean }}=1$, in agreement with our findings and with previous numerical simulations [Tackley, 1998; Montague and Kellogg, 2000].

[60] The variation of $\alpha$ with depth is, however, of fundamental importance, since the regime of a given twolayer system will change with the location of the interface [Davaille, 1999b]. For instance, as shown in Figure 8, the whole layer regime for a $1 \%$ chemical stratification in the midmantle corresponds to a temperature contrast of $340 \mathrm{~K}$, taking $\alpha=3 \times 10^{-5} \mathrm{~K}^{-1}$ [Poirier, 1991]. The same thermal anomaly at the base of the mantle, where $\alpha \sim 10^{-5} \mathrm{~K}^{-1}$ [Poirier, 1991], gives an effective buoyancy number $B_{\text {eff }}=$ 2.9, which corresponds to a stratified regime. This mechanism could explain the simultaneous generation of hot spots (Figure 2b) and superswells (Figure 2e) from a single geochemical reservoir [Davaille, 1999b]. The $\mathrm{D}^{\prime \prime}$ layer, a region of seismic anomalies interpreted as a chemically distinct dense layer at the base of the mantle [Davies and Gurnis, 1986; Hansen and Yuen, 1988; Lay et al., 1998], would then correspond to the lower stratified part of this reservoir.

[61] One can also notice that as a dome rises, the slow increase of the thermal expansion coefficient makes thermal effects more important and decreases the buoyancy number: the dome thus becomes more and more buoyant as it comes closer to the surface, an effect which might enhance the dome velocity. In the more drastic case of a steep gradient or even a step function of the thermal expansion coefficient, 
the local buoyancy number could locally exceed $B_{c}$, which would stabilize the flow. This effect has been seen in recent numerical experiments (U. Hansen, personal communication, 2003).

\subsection{The 660-km Phase Transition}

[62] The major seismic discontinuity in the mantle takes place around $660 \mathrm{~km}$ depth over a very narrow interval. It is due to an endothermic phase transition [Ito and Takahashi, 1989], possibly coupled with a change in bulk composition [Schubert et al., 2001, p. 88].

[63] As observed by Schubert et al. [1975], an endothermic phase change has a twofold effect on hot rising plumes: on the one hand, the temperature excess induces an upward deflection of the transition depth, thus creating a negative buoyancy force compared to the surrounding mantle; on the other hand, the latent heat release from the phase change induces an extra heating of the convective feature, thus a positive buoyancy force. The overall effect is to delay the passage of the structure, all the more when it is less viscous. When the negative Clapeyron slope is too strong, heat diffusion cancels the plume thermal buoyancy before it penetrates the upper mantle [Nakakuki et al., 1994; Schubert et al., 1995].

[64] One can expect the same mechanism to act on our large-scale thermochemical structures. The passage of a dome will be even more difficult because of its chemical stratification, as demonstrated by the following mechanistic model. Let $\theta$ be the typical temperature excess of the rising structure and $d$ be its typical size. $\theta$ decreases through time because of heat diffusion: in a simple scaling analysis,

$$
\begin{gathered}
\frac{\partial \theta}{d t} \sim-\kappa \frac{\theta}{d^{2}} \\
\theta \sim \theta_{0} \exp \left(-\frac{t}{d^{2} / \kappa}\right) .
\end{gathered}
$$

The dome begins to sink when the effective density contrast given by equation (15) reaches zero, so at time

$$
t_{\text {down }} \sim-\frac{d^{2}}{\kappa} \ln \left(\frac{\Delta \rho_{\chi}}{\alpha \rho \theta_{0}}\right) .
$$

$\theta_{0}$ corresponds to the temperature excess at the onset of destabilization, thus according to equations (12) and (14),

$$
t_{\text {down }} \sim-\frac{d^{2}}{\kappa} \ln \left(B_{c}\right) \sim 0.02 \frac{d^{2}}{\kappa} .
$$

Penetration in the upper mantle is possible when the delay induced by the phase change is smaller than $t_{\text {down }}$. In the case of purely thermal plumes, the same type of study gives

$$
t_{\text {down,plume }} \sim \frac{d^{2}}{\kappa} \text {. }
$$

The penetration of a thermochemical structure is more difficult than the penetration of a thermal feature of the same size. However, domes are also larger than plumes, a)

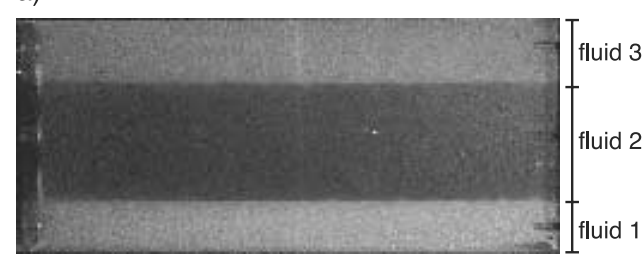

b)

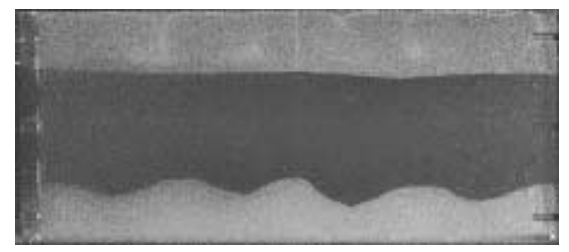

c)

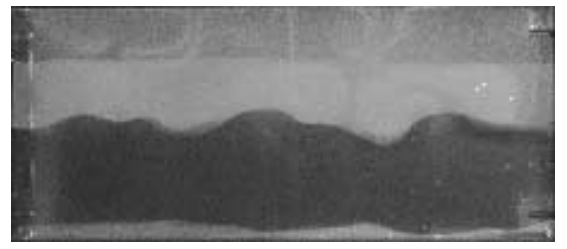

d)

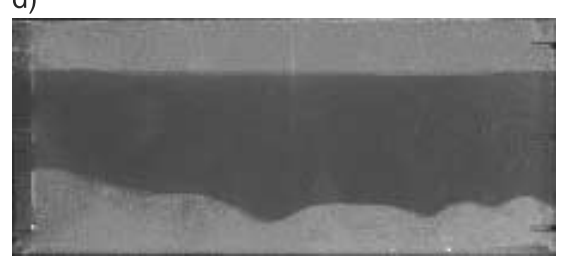

Figure 18. Experiment with three layers $\left(h_{1}=3.0 \mathrm{~cm}, h_{2}=\right.$ $7.8 \mathrm{~cm}, h_{3}=4.0 \mathrm{~cm}, \gamma_{1-2}=56, \gamma_{2-3}=3.6, B_{1-2}=0.24$, $B_{2-3}=1.46, R a=4.4 \times 10^{7}$ ): (a) $t=0 \mathrm{~min}$, (b) $t=12 \mathrm{~min}$, (c) $t=17 \mathrm{~min}$, and (d) $t=24 \mathrm{~min}$. See color version of this figure in the HTML.

which counterbalances the previous effect (larger $d$ implies larger $t_{\text {down }}$ thus easier penetration, as observed in the numerical model by Tackley [1995]).

[65] Impeded structures have, however, important effects on the upper mantle: as shown by Steinbach and Yuen [1997], they spread laterally under the transition zone and create (1) a low-viscosity zone separating upper and lower mantles and (2) a source of secondary plumes in the upper mantle. Since we can not realize a phase transition in our tank, this effect has been illustrated by a three-layer experiment, where the density contrast between the lower layer 1 and the central layer 2 allows a whole layer regime, whereas the density contrast between the central layer 2 and the upper layer 3 corresponds to a stable stratification. As shown in Figure 18, domes then rise from the first interface, until they are trapped by the second one; a thermal boundary layer then grows between fluids 1 and 3, and gives rise to thermochemical plumes in the upper layer. Such a situation seems to take place in the Pacific superswell [Vinnik et al., 1997]: the "secondary plumes" [Davaille, 1999b; Courtillot et al., 2002] created at the $660 \mathrm{~km}$ interface then generate the multiple short-lived hot spots observed at the surface [McNutt, 1998]. 
[66] To finish with, one must notice that the penetrability of the 660-km transition depends on the vigor of convection [Christensen and Yuen, 1985; Zhao et al., 1992; Yuen et al., 1994] and has thus evolved through time. In thermochemical convection, this will be even more complicated by the simultaneous influence of $B$ and $R a$, which both change through Earth's history. Besides, other phase transitions are also present in the mantle and will affect the dynamics [e.g., Steinbach and Yuen, 1997]. Hence more work is necessary to complete the first-order conclusions proposed here.

\subsection{Influence of Plate Tectonics}

[67] Plate tectonics is the most important "Earth ingredient" missing in our tank, since it is the surface signature of the largest scale of convection on Earth. The latter is characterized by rigid, two-dimensional, cold sinking currents, whose distribution seems to delimit today two "boxes" in Earth's mantle, with the mantle under the Pacific isolated from the rest of the mantle by its subduction belt.

[68] The existence of this form of convection is due to the complex rheology of mantle material [e.g., Bercovici, 2003]. Since we use material with newtonian rheology, this type of convection is absent in our experiment (indeed, we do not observe any two-dimensional (2-D), rigid, cold structures). Therefore our results are quantitatively valid for Earth's mantle when they are describing a phenomenon which happens on temporal and spatial scales smaller than plate tectonics scales, i.e., a phenomenon with lateral extent less than a few thousands kilometers (within one box) and a duration less than a few hundred million years (within a box lifetime). In that respect, our inferences on superswell formation and thermochemical instabilities are probably well grounded. On longer timescales, the time evolution of the mantle could be quite different from what we can predict from the scaling laws determined in our study for two reasons:

[69] 1. Subduction acts to reintroduce chemical heterogeneities in the mantle, and therefore could replenish or build new reservoirs [Davies, 1984; Gurnis, 1986; Christensen and Hofmann, 1994; Albarède, 1998; Coltice and Ricard, 1999; Albarède and Van der Hilst, 2002]. The convective history in our experiments is determined, on the contrary, by the continuous erasing of initial heterogeneities by mixing. We are therefore lacking a critical source term.

[70] 2. Stirring and mixing by cellular time-dependent 2-D structures, as present in the mantle, is probably different from mixing produced by the 3-D chaotic convection obtained in our experiments [e.g., Christensen, 1989; Schmalzl et al., 1996; Ferrachat and Ricard, 1998]. Hence our mixing scaling laws may be erroneous for the Earth since they do not describe exactly the same mixing phenomenon.

[71] To estimate this effect requires more work with plate tectonic convection.

\section{Conclusion}

[72] Earth's mantle is heterogeneous: it consists of several reservoirs with different densities and viscosities, which survive over very long times, while authorizing motions over the whole system. To study its dynamics, we have focused on a simple case of heterogeneous convection: two fluids with different densities, viscosities and depths are superimposed in a tank, then heated from below and cooled from above. Our purpose is not to build a miniature Earth: the natural complications are too many to be integrated in a single model (even numerical); besides, the precise characteristics of the chemical heterogeneities are yet only partially known. However, we tried (1) to systematically quantify the influence of density and viscosity contrasts on dynamics of the two-layer system and (2) to characterize the whole range of behaviors that may take place in planetary mantles.

[73] In the present paper, we have focused on the whole layer regime, i.e., on cases where the interface largely deforms and motions propagate over the whole depth of the system. Provided the viscosity ratio is larger than 5 , a pulsatory mode then takes place and persists for a very long time (i.e., hundreds of millions of years in planetary mantles). This regime is particularly interesting, since it offers a simple physical explanation to the great geological crises generally observed on terrestrial planets, and more specifically to the superswells observed at present on Earth.

[74] Our analogical model addresses the problem of mantle convection from a fluid dynamics point of view, starting from existing reservoirs. The physics of the described phenomena are robust: they are based on a local approach taking into account local density, viscosity and temperature contrasts around the interface of a given reservoir. Main conclusions regarding the dynamics, and especially the occurrence of doming or stratified convection which depends only on the value of the local buoyancy ratio across the interface, will thus remain unchanged when taking into account more Earth-like ingredients, as for instance the presence of continents or of a phase transition, which could both also create episodicity. The reconstruction of the whole evolution of the mantle will now demand to integrate the continuing processes of creation of chemical heterogeneities through plate tectonics, which corresponds to the order zero of mantle convection.

[75] Acknowledgments. This work benefited from fruitful discussions with Cinzia Farnetani, Claude Jaupart, Neil Ribe, Henri Samuel, and from the thoughtful reviews of Francis Albarède, Marc Parmentier, Norm Sleep and an anonymous editor. This research has been supported by the French INSU programs IDYL and IT. This is an IPGP contribution.

\section{References}

Albarède, F. (1998), Time-dependent models of U-Th-He and K-Ar evolution and the layering of mantle convection, Chem. Geol., 145, 413-429. Albarède, F., and R. Van der Hilst (2002), Zoned mantle convection, Philos. Trans. R. Soc. London, Ser. A, 360, 2569-2592.

Allègre, C. J. (1987), Isotope geodynamics, Earth Planet. Sci. Lett., 86, $175-203$

Allègre, C. J. (1997), Limitation on the mass exchange between the upper and lower mantle: The evolving convection regime of the Earth, Earth Planet. Sci. Lett., 150, 1-6.

Allègre, C. J., D. B. Othman, M. Polve, and P. Richard (1979), The Nd-Sr isotopic correlation in mantle materials and geodynamic consequences, Earth Planet. Sci. Lett., 81, 319-337.

Baker, V. R., R. G. Strom, V. C. Gulick, J. S. Kargel, G. Komatsu, and V. S. Kale (1991), Ancient oceans, ice sheets and the hydrological cycle on Mars, Nature, 352, 589-594.

Becker, T. W., J. B. Kellogg, and R. J. O’Connell (1999), Thermal constraints on the survival of primitive blobs in the lower mantle, Earth Planet. Sci. Lett., 171, 351-365.

Bercovici, D. (2003), The generation of plate tectonics from mantle convection, Earth Planet. Sci. Lett., 205, 107-121.

Bina, C. R. (1998), Lower mantle mineralogy and the geophysical perspective, in Ultra-high Pressure Mineralogy, Rev. Mineral., vol. 37, edited by R. J. Hemley, Am. Mineral. Soc., Washington, D. C. 
Brunet, D., and P. Machetel (1998), Large-scale tectonic features induced by mantle avalanches with phase, temperature, and pressure lateral variations of viscosity, J. Geophys. Res., 103, 4929-4946.

Caldeira, K., and M. R. Rampino (1991), The mid-Cretaceous superplume, carbon dioxide, and global warming, Geophys. Res. Lett., 18, 987-990.

Cazenave, A., and C. Thoraval (1994), Mantle dynamics constrained by degree 6 surface topography, seismic tomography and geoid: Inference on the origin of the south Pacific superswell, Earth Planet. Sci. Lett., 122 , 207-219.

Cazenave, A., A. Souriau, and K. Dominh (1989), Global coupling of Earth surface topography with hotspots, geoid and mantle heterogeneities, Nature, 340, 54-57.

Christensen, U. R. (1989), Mixing by time-dependent convection, Earth Planet. Sci. Lett., 95, 382-394.

Christensen, U. R. (1995), Effects of phase transitions on mantle convection, Annu. Rev. Earth Planet. Sci., 23, 65-87.

Christensen, U. R., and A. W. Hofmann (1994), Segregation of subducted oceanic crust in the convecting mantle, J. Geophys. Res., 99, 19,86719,884 .

Christensen, U. R., and D. A. Yuen (1985), Layered convection induced by phase transitions, J. Geophys. Res., 90, 10,291-10,300.

Coltice, N., and Y. Ricard (1999), Geochemical observations and one layer mantle convection, Earth Planet. Sci. Lett., 174, 125-137.

Condie, K. C. (1998), Episodic continental growth and supercontinents: A mantle avalanche connection?, Earth Planet. Sci. Lett., 163, 97-108.

Condie, K. C. (2002), Superplume events in Earth history, paper presented at Superplume Workshop, Tokyo Inst. of Technol., Tokyo.

Courtillot, V., and J. Besse (1987), Magnetic-field reversals, polar wander and core-mantle coupling, Science, 237, 1140-1147.

Courtillot, V., J. J. Jaeger, Z. Yang, G. Feraud, and C. Hofmann (1996), The influence of continental flood basalts on mass extinctions: Where do we stand?, in Proceedings of Conference on New Developments Regarding the KT Event and Other Catastrophes in Earth History, edited by G. Ryder, D. Fastovsky, and S. Gartner, Spec. Pap. Geol. Soc. Am., 307, 513-525.

Courtillot, V., A. Davaille, J. Besse, and J. Stock (2002), Three distinct types of hotspots in the Earth's mantle, Earth Planet. Sci. Lett., 205 , $295-308$.

Cox, A. (1982), Magnetostratigraphic time scale, in A Geologic Time Scale, edited by W. B. Harland et al., pp. 63-84, Cambridge University Press, New York.

Davaille, A. (1999a), Two-layer thermal convection in miscible fluids, J. Fluid Mech., 379, 223-253.

Davaille, A. (1999b), Simultaneous generation of hotspots and superswells by convection in a heterogeneous planetary mantle, Nature, 402, 756760

Davaille, A., F. Girard, and M. Le Bars (2002), How to anchor hot spots in a convecting mantle?, Earth Planet. Sci. Lett., 203, 621-634.

Davaille, A., M. Le Bars, and C. Carbonne (2003), Thermal convection in an heterogeneous mantle, C. R. Geosci., 335, 141-156.

Davies, G. F. (1984), Geophysical and isotopic constraints on mantle convection: An interim synthesis, J. Geophys. Res., 89, 6017-6040.

Davies, G. F., and M. Gurnis (1986), Interaction of mantle dregs with convection: Lateral heterogeneity at the core-mantle boundary, Geophys. Res. Lett., 13, 1517-1520.

DePaolo, D., and G. J. Wasserburg (1976), Inferences about magma sources and mantle structure from variations of ${ }^{143} \mathrm{Nd} /{ }^{144} \mathrm{Nd}$, Geophys. Res. Lett., 3, $743-746$.

Dziewonski, A. M., and D. L. Anderson (1981), Preliminary reference Earth model, Phys. Earth Planet. Int., 25, 297-356.

Dziewonski, A. M., and J. H. Woodhouse (1987), Global images of the Earth's interior, Science, 236, 37-48.

Ferrachat, S., and Y. Ricard (1998), Regular vs. chaotic mantle mixing, Earth Planet. Sci. Lett., 155, 75-86.

Forte, A. M., and J. X. Mitrovica (2001), Deep-mantle high-viscosity flow and thermochemical structure inferred from seismic and geodynamic data, Nature, 410, 1049-1056.

Forte, A. M., J. X. Mitrovica, and R. L. Woodward (1995), Seismicgeodynamic determination of the origin of excess ellipticity of the core-mantle boundary, Geophys. Res. Lett., 22, 1013-1016.

Fukao, Y., S. Widiyantoro, and M. Obayashi (2001), Stagnant slabs in the upper and lower mantle transition region, Rev. Geophys., 39, 291-324.

Gallet, Y., and G. Hulot (1997), Stationary and nonstationary behaviour within the geomagnetic polarity time scale, Geophys. Res. Lett., 24, $1875-1878$.

Garzanti, E. (1993), Himalayan ironstones, 'superplumes', and the breakup of Gondwana, Geology, 21, 105-108.

Grand, S. P., R. D. Van der Hilst, and S. Widiyantoro (1997), High resolution global tomography: A snapshot of convection in the Earth, Geol. Soc. Am. Today, 7, 1-7.
Greeley, R., and B. D. Schneid (1991), Magma generation on Mars: Amounts, rates and comparisons with Earth, Moon and Venus, Science, 254, 996-998.

Gubbins, D. (1994), Geomagnetic polarity reversals: A connection with secular variation and core-mantle interaction?, Rev. Geophys., 32, 61-83.

Guillou, L., and C. Jaupart (1995), On the effect of continents on mantle convection, J. Geophys. Res., 100, 24,217-24,238.

Gurnis, M. (1986), The effects of chemical density differences on convective mixing in the Earth's mantle, J. Geophys. Res., 91, 11,407-11,419.

Gurnis, M., J. X. Mitrovica, J. Ritsema, and H.-J. Van Heijst (2000), Constraining mantle density structure using geological evidence of surface uplift rates: The case of the African superplume, Geochem. Geophys. Geosyst., 1, Paper number 1999GC000035.

Guyot, F., M. Madon, J. Peyronneau, and J.-P. Poirier (1988), X-ray microanalysis of high-pressure/high-temperature phases synthesized from natural olivine in a diamond-anvill cell, Earth Planet. Sci. Lett., 90, 52-64.

Hansen, U., and D. A. Yuen (1988), Numerical simulations of thermalchemical instabilities at the core-mantle boundary, Nature, 334, $237-$ 240

Hansen, U., and D. A. Yuen (2000), Extended-Boussinesq thermal-chemical convection with moving heat sources and variable viscosity, Earth Planet. Sci. Lett., 176, $401-411$.

Herrick, D. L., and E. M. Parmentier (1994), Episodic large-scale overturn of two-layer mantles in terrestrial planets, J. Geophys. Res., 99, $2053-$ 2062.

Hofmann, A. W. (1997), Mantle geochemistry: The message from oceanic volcanism, Nature, 385, 219-229.

Ishii, M., and J. Tromp (1999), Normal-mode and free-air gravity constraints on lateral variations in velocity and density of Earth's mantle, Science, 285, 1231-1236.

Isley, A. E., and D. H. Abbott (1999), Plume-related mafic volcanism and the deposition of banded iron formation, J. Geophys. Res., 104, 15,46115,477 .

Ito, E., and E. Takahashi (1989), Post-spinel transformations in the system $\mathrm{Mg}_{2} \mathrm{SiO}_{4}-\mathrm{Fe}_{2} \mathrm{SiO}_{4}$ and some geophysical implications, J. Geophys. Res., 94, 10,637-10,646

Jackson, I. (1998), Elasticity, composition and temperature of the Earth's lower mantle: A reappraisal, Geophys. J. Int., 134, 291-311.

Jacobsen, S. B., and G. J. Wasserburg (1979), The mean age of mantle and crustal reservoirs, J. Geophys. Res., 84, 7411-7428.

Karato, S., and P. Wu (1993), Rheology of the upper mantle: A synthesis, Science, 260, 771-778.

Kargel, J. S., and R. G. Strom (1992), Ancient glaciation on Mars, Geology, $62,310-316$

Kellogg, L. H., B. H. Hager, and R. D. Van der Hilst (1999), Compositional stratification in the deep mantle, Science, 283, 1881-1884.

Labrosse, S. (2002), Hotspots, mantle plumes and core heat loss, Earth Planet. Sci. Lett., 199, 147-156.

Larson, R. L. (1991), Geological consequences of superplumes, Geology, $19,963-966$.

Larson, R. L., and P. Olso (1991), Mantle plumes control magnetic reversal frequency, Earth Planet. Sci. Lett., 107, 437-447.

Lay, T., Q. Williams, and E. J. Garnero (1998), The core-mantle boundary layer and deep Earth dynamics, Nature, 392, 461-467.

Le Bars, M., and A. Davaille (2002), Stability of thermal convection in two superimposed miscible viscous fluids, J. Fluid Mech., 471, 339-363.

Le Bars, M., and A. Davaille (2004), Large interface deformation in twolayer thermal convection of miscible viscous fluids, J. Fluid Mech., 499, $75-110$.

Li, X.-D., and B. Romanowicz (1996), Global mantle shear velocity model developed using nonlinear asymptotic coupling theory, J. Geophys. Res., $101,22,245-22,272$.

Lithgow-Bertelloni, C., and P. G. Silver (1998), Dynamic topography, plate driving forces and the African superswell, Nature, 395, 269-272.

Machetel, P., and P. Weber (1991), Intermittent layered convection in a model mantle with an endothermic phase change at $670 \mathrm{~km}$, Nature, 350, 55-57.

Manga, M. (1996), Mixing of heterogeneities in the mantle: Effects of viscosity differences, Geophys. Res. Lett., 23, 403-406.

Matsui, M. (2000), Molecular dynamics simulation of $\mathrm{MgSiO}_{3}$ perovskite and the $660 \mathrm{~km}$ seismic discontinuity, Phys. Earth Planet. Inter., 121, $77-84$.

Matsui, M., S. C. Parker, and M. Leslie (2000), The MD simulation of the equation of state of $\mathrm{MgO}$ : Application as a pressure calibration standard at high temperature and high pressure, Am. Mineral., 85, 312-316.

McKenzie, D., and F. M. Richter (1981), Parameterized convection in a layered region and the thermal history of the Earth, J. Geophys. Res., 86, $11,667-11,680$

McKenzie, D., J. Roberts, and N. Weiss (1974), Convection in the Earth's mantle: Towards a numerical simulation, J. Fluid Mech., 62, 465-538. 
McNutt, M. K. (1998), Superswells, Rev. Geophys., 36, 211-244.

McNutt, M. K., and K. M. Fisher (1987), The South Pacific superswell, in Seamounts, Islands and Atolls, Geophys. Monogr. Ser., vol. 43, edited by B. H. Keating et al., pp. 25-34, AGU, Washington, D. C.

McNutt, M. K., and A. V. Judge (1990), The superswell and mantle dynamics beneath the South Pacific, Science, 248, 969-975.

Ménard, H. W. (1964), Marine Geology of the Pacific, McGraw-Hill, New York.

Merrill, R. T., and P. L. McFadden (1995), Dynamo theory and paleomagnetism, J. Geophys. Res., 100, 317-326.

Merrill, R. T., and P. L. McFadden (1999), Geomagnetic polarity transitions, Rev. Geophys., 37, 201-226.

Merveilleux du Vignaux, N., and L. Fleitout (2001), Stretching and mixing of viscous blobs in Earth's mantle, J. Geophys. Res., 106, 30,89330,909 .

Montague, N. L., and L. H. Kellogg (2000), Numerical models of a dense layer at the base of the mantle and implications for the geodynamics of $\mathrm{D}^{\prime \prime}$, J. Geophys. Res., 105, 11,101-11,114

Nakakuki, T., H. Sato, and H. Fujimoto (1994), Interaction of the upwelling plume with the phase and chemical boundary at the $670 \mathrm{~km}$ discontinuity-effects of temperature-dependent viscosity, Earth Planet. Sci. Lett., $121,369-384$

Ni, S., E. Tan, M. Gurnis, and D. Helmberger (2002), Sharp sides to the African superplume, Science, 296, 1850-1852.

Nyblade, A. A., and S. W. Robinson (1994), The African superswell, Geophys. Res. Lett., 21, 765-768.

Olson, P. (1984), An experimental approach to thermal convection in a twolayered mantle, J. Geophys. Res., 89, 11,293-11,301.

Olson, P., and C. Kincaid (1991), Experiments on the interaction of thermal convection and compositional layering at the base of the mantle, J. Geophys. Res., 96, 4347-4354.

Olson, P., and H. Singer (1985), Creeping plumes, J. Fluid Mech, 158, $511-531$.

O’Nions, R. K., N. M. Evensen, and P. J. Hamilton (1979), Variations in ${ }^{143} \mathrm{Nd} /{ }^{144} \mathrm{Nd}$ and ${ }^{87} \mathrm{Sr} /{ }^{86} \mathrm{Sr}$ ratios in oceanic basalts, Earth Planet. Sci. Lett. , 34, 13-22.

Poirier, J.-P. (1991), Introduction to the Physics of the Earth's Interior, Cambridge Univ. Press, New York.

Ray, J. S., and K. Pande (1999), Carbonatite alkaline magmatism associated with continental flood basalts at stratigraphic boundaries: Cause for mass extinctions, Geophys. Res. Lett., 26, 1917-1920.

Ribe, N. M. (1998), Spouting and planform selection in the RayleighTaylor instability of miscible viscous fluids, J. Fluid Mech., 377, 27-45. Richards, M. A., and D. C. Engebretson (1992), Large scale mantle convection and the history of subduction, Nature, 355, 437-440.

Richards, M. A., R. A. Duncan, and V. E. Courtillot (1989), Flood basalts and hot-spot tracks: Plume heads and tails, Science, 246, 103-107.

Richter, F. M., and C. E. Johnson (1974), Stability of a chemically layered mantle, J. Geophys. Res., 79, 1635-1639.

Ritsema, J., S. Ni, D. V. Helmberger, and H. P. Crotwell (1998), Evidence for strong shear velocity reductions and velocity gradients in the lower mantle beneath Africa, Geophys. Res. Lett., 25, 245-248.

Roberston, G. S., and J. H. Woodhouse (1996), Ratio of relative $S$ to $P$ velocity heterogeneity in the lower mantle, J. Geophys. Res., 101, $20,041-20,052$

Romanowicz, B., and Y. Gung (2002), Superplumes from the core-mantle boundary to the lithosphere: Implications for heat flux, Science, 296, $513-516$

Samuel, H., and C. G. Farnetani (2001), A denser and relatively undegassed lower mantle reservoir: Geochemical and seismological model predictions, Eos Trans. $A G U, 82(47)$, Fall Meet. Suppl., Abstract T21A-0874

Samuel, H., and C. G. Farnetani (2003), Thermochemical convection and helium concentrations in mantle plumes, Earth Planet. Sci. Lett., 207, $39-56$.

Schmalzl, J., G. A. Houseman, and U. Hansen (1996), Mixing in vigorous, time-dependent three-dimensional convection and application to Earth's mantle, J. Geophys. Res., 101, 21,847-21,858.

Schubert, G., D. Yuen, and D. L. Turcotte (1975), Role of phase transitions in a dynamic mantle, Geophys. J. R. Astron. Soc., 42, 705-735.

Schubert, G., C. Anderson, and P. Goldman (1995), Mantle plume interaction with an endothermic phase change, J. Geophys. Res., 100, $8245-$ 8256

Schubert, G., D. L. Turcotte, and P. Olson (2001), Mantle Convection in the Earth and Planets, Cambridge Univ. Press, New York.

Sheridan, R. E. (1983), Phenomena of pulsation tectonics related to the breakup of the eastern North American continental margin, Tectonophysics, 94, 169-185.

Solheim, L. P., and W. R. Peltier (1994), Avalanche effects in phase transition modulated thermal convection: A model of Earth's mantle, J. Geophys. Res., 99, 6991-7018.
Staudigel, H., K.-H. Park, M. Pringle, J. L. Rubenstone, W. H. F. Smith, and A. Zindler (1991), The longevity of the south Pacific isotopic and thermal anomaly, Earth Planet. Sci. Lett., 102, 24-44.

Stein, M., and A. W. Hofmann (1994), Mantle plumes and episodic crustal growth, Nature, 372, 63-68.

Steinbach, V., and D. A. Yuen (1997), The influences of temperature- and pressure-dependent lower-mantle rheology on the interaction of upwellings with phase transitions, Phys. Earth Planet. Inter, 103, 85-100.

Strom, R. G., G. G. Schaber, and D. D. Dawson (1994), The global resurfacing of Venus, J. Geophys. Res., 99, 10,899-10,926.

$\mathrm{Su}$, W., and A. M. Dziewonski (1997), Simultaneous inversion from 3-D variations in shear and bulk velocity in the mantle, Phys. Earth Planet. Inter., $100,135-156$

Sumita, I., and P. Olson (1999), A laboratory model for convection in the Earth's core driven by a thermally heterogeneous mantle, Science, 286, $1547-1549$.

Tackley, P. J. (1995), On the penetration of an endothermic phase transition by upwellings and downwellings, Science, 100, 15,477-15,488.

Tackley, P. J. (1998), Three-dimensional simulations of mantle convection with a thermochemical CMB boundary layer: $\mathrm{D}^{\prime \prime}$ ?, in The Core Mantle Boundary Region, Geodyn. Ser., vol. 28, edited by M. Gurnis et al., pp. 231-253, AGU, Washington, D. C.

Tackley, P. J. (2000), Mantle convection and plate tectonics: Toward an integrated physical and chemical theory, Science, 288, 2002-2007.

Tackley, P. J. (2002), Strong heterogeneity caused by deep mantle layering, Geochem. Geophys. Geosyst., 3(4), 1024, doi:10.1029/2001GC000167.

Tackley, P. J., D. J. Stevenson, G. A. Glatzmaier, and G. Schubert (1993), Effects of an endothermic phase transition at $670 \mathrm{~km}$ depth in a spherical model of convection in the Earth's mantle, Nature, 361, 699-704.

Tanaka, K. L., and M. G. Chapman (1992), Kasei Valles, Mars: Interpretation of canyon materials and flood sources, Proc. Lunar Planet. Sci. Conf., 22, 73-83.

Utsunomiya, A., N. Suzuki, and S. Maruyama, (2002), The history of the Pacific superplume, paper presented at Superplume Workshop, Tokyo Inst. of Technol., Tokyo.

Van der Hilst, R. D., S. Widiyantoro, and E. R. Engdahl (1997), Evidence for deep mantle circulation from global tomography, Nature, 386, 578584.

Van Keken, P. E., E. H. Hauri, and C. J. Ballentine (2002), Mantle mixing: The generation, preservation and destruction of chemical heterogeneity, Annu. Rev. Earth Planet. Sci. Lett., 30, 493-525.

Vidale, J. E., G. Schubert, and P. S. Earle (2001), Unsuccessful initial search for a midmantle chemical boundary layer with seismic arrays, Geophys. Res. Lett., 28, 859-862.

Vinnik, L., S. Chevrot, and J.-P. Montagner (1997), Evidence for a stagnant plume in the transition zone?, Geophys. Res. Lett., 24, 1007-1010.

Wang, Y., and D. J. Weidner $(1996),(\partial \mu / \partial t)_{P}$ of the lower mantle, Pure Appl. Geophys, 146, 533-549.

Weinstein, S. A. (1993), Catastrophic overturn of the Earth's mantle driven by multiple phase changes and internal heat generation, Geophys. Res. Lett., 20, 101-104

White, R., and D. McKenzie (1989), Magmatism at rift zones: The generation of volcanic continental margins and flood basalts, J. Geophys. Res. $94,7685-7729$

Whitehead, J. A., and D. S. Luther (1975), Dynamics of laboratory diapir and plume models, J. Geophys. Res., 80, 705-717.

Wilson, J. T. (1966), Did the Atlantic close and then re-open?, Nature, 211, $676-681$

Winterer, E. L., J. H. Natland, R. J. Van Waasbergen, R. A. Duncan, M. K. McNutt, C. J. Wolfe, I. P. Silva, W. W. Sager, and W. V. Sliter (1993), Cretaceous guyots in the northwest Pacific: An overview of their geology and geophysics, in The Mesozoic Pacific: Geology, Tectonics and Volcanism, Geophys. Monogr. Ser., vol. 77, edited by M. S. Pringle et al., pp. 307-334, AGU, Washington, D. C.

Yuen, D. A., O. Cadek, A. Chopelas, and C. Matyska (1993), Geophysical inferences of thermal-chemical structures in the lower mantle, Geophys. Res. Lett., 20, 899-902.

Yuen, D. A., D. M. Reuteler, S. Balachandar, V. Steinbach, A. V. Malevsky, and J. L. Smedsmo (1994), Various influences on three-dimensional mantle convection with phase transitions, Phys. Earth Planet. Inter. $86,185-203$

Zhao, M., D. A. Yuen, and S. Honda (1992), Multiple phase transitions and the style of mantle convection, Phys. Earth Planet. Inter., 72, 185-210.

A. Davaille and M. Le Bars, Laboratoire de Dynamique des Systèmes Géologiques, Institut de Physique du Globe de Paris/CNRS UMR 7579, 4 place Jussieu, boîte 89, F-75252 Paris cedex 05, France. (davaille@ipgp. jussieu.fr; lebars@ipgp.jussieu.fr) 